\title{
Effect of Parametric Uncertainties, Variations, and Tolerances on Thermohydraulic Performance of Flat Plate Solar Air Heater
}

\author{
Rajendra Karwa ${ }^{1}$ and Shweta Baghel ${ }^{2}$ \\ ${ }^{1}$ Jodhpur Institute of Engineering \& Technology, Mogra, N.H. 65, New Pali Road, Jodhpur 342082, India \\ ${ }^{2}$ Department of Mechanical Engineering, Faculty of Engineering \& Architecture, Jai Narain Vyas University, Jodhpur 342001, India \\ Correspondence should be addressed to Rajendra Karwa; karwa_r@yahoo.com
}

Received 17 May 2014; Revised 25 August 2014; Accepted 26 August 2014; Published 21 September 2014

Academic Editor: Antonio Lecuona

Copyright ( 2014 R. Karwa and S. Baghel. This is an open access article distributed under the Creative Commons Attribution License, which permits unrestricted use, distribution, and reproduction in any medium, provided the original work is properly cited.

\begin{abstract}
The paper presents results of an analysis carried out using a mathematical model to find the effect of the uncertainties, variations, and tolerances in design and ambient parameters on the thermohydraulic performance of flat plate solar air heater. Analysis shows that, for the range of flow rates considered, a duct height of $10 \mathrm{~mm}$ is preferred from the thermohydraulic consideration. The thermal efficiency changes by about $2.6 \%$ on variation in the wind heat transfer coefficient, $\pm 5 \mathrm{~K}$ variation in sky temperature affects the efficiency by about $\pm 1.3 \%$, and solar insolation variation from 500 to $1000 \mathrm{Wm}^{-2}$ affects the efficiency by about -1.5 to $1.3 \%$ at the lowest flow rate of $0.01 \mathrm{kgs}^{-1} \mathrm{~m}^{-2}$ of the absorber plate with black paint. In general, these effects reduce with increase in flow rate and are lower for collector with selective coating on the absorber plate surface. The tolerances in the duct height and absorber plate emissivity should be small while positive tolerance of $3^{\circ}$ in the collector slope for winter operation and $\pm 3^{\circ}$ for year round operation, and a positive tolerance for the gap between the absorber plate and glass cover at nominal value of $40 \mathrm{~mm}$ are recommended.
\end{abstract}

\section{Introduction}

Solar energy, a renewable energy source, is readily converted into heat using a solar collector. The simplest and the most common design of a solar collector used to heat air for space heating, drying applications, or similar industrial application is shown in Figure 1(a), wherein the air is propelled through the rectangular duct of the air heater behind a flat aluminium or steel absorber plate with the help of a blower or fan. One or two transparent covers are placed at a gap over the absorber plate to arrest the heat loss in the upward direction from the heated absorber plate. The collector is usually installed facing south to receive maximum solar radiation. The sunfacing side of the absorber plate is painted black for high solar radiation absorptance.

Figure 1(b) depicts the energy flow in a solar air heater with single glass cover. A part of the solar radiation absorbed at the absorber plate surface is transferred to the air flowing through the air heater duct and is the useful heat gain. Remaining energy is lost to the surroundings and sky through the glass cover, back and edges of the air heater, and is termed as heat loss from the collector.

The heat transfers from the heated absorber plate to the inner surface of the glass cover by free convection and radiation, through the cover by conduction, and from the outer surface of the cover by convection to the ambient and radiation to the sky. The convection heat loss from the absorber plate to the cover is minimized by optimizing the air gap between them. Selective coating on the absorber plate surface, which has high solar radiation absorptivity and low long wave emissivity, can further reduce the radiation heat loss from the absorber plate. Despite these measures, the heat loss from the top of the collector is a major contributor to the overall heat loss from a flat plate collector. The losses from the back and edge of the collector are not significant and can be arrested by providing adequate insulation.

Using the transformations of Karwa et al. [1], the dependence of the collector performance on the duct dimensions and air flow rate per unit area of the absorber plate can be shown. 


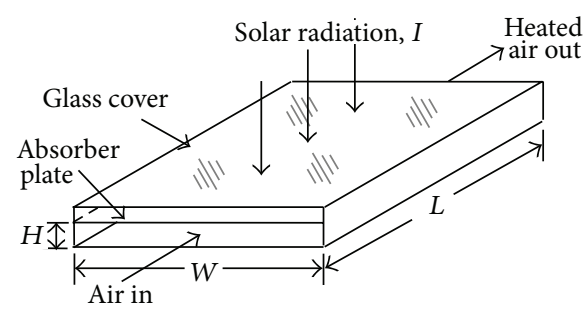

(a)

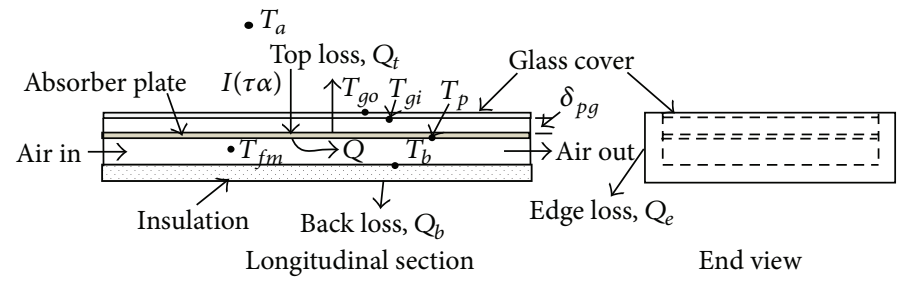

(b)

Figure 1: (a) Schematic diagram of a solar air heater and (b) heat balance.

The Reynolds number $\left(=\dot{m} D_{h} / \mu\right)$ can be expressed in a simple form, considering the fact that, for the high aspect ratio rectangular duct of solar air heater (typically width $W$ is of the order of $1 \mathrm{~m}$ and duct height $H=5-20 \mathrm{~mm}$ ), the hydraulic diameter $D_{h} \approx 2 \mathrm{H}$,

$$
\begin{aligned}
\operatorname{Re} & =\frac{\dot{m} D_{h}}{\mu}=\frac{1}{\mu}\left(\frac{A G}{W H}\right)(2 H)=\frac{1}{\mu}\left(\frac{W L G}{W H}\right)(2 H) \\
& =\frac{2 G L}{\mu},
\end{aligned}
$$

where $\dot{m}$ is the mass velocity, $A(=W L)$ is the area of the absorber plate, and $G$ is the mass flow rate per unit area of the absorber plate.

The thermal efficiency $\eta$ of a solar air heater is a ratio of the useful heat gain $Q$ and the incident solar radiation $I$ on the collector plane; that is,

$$
\eta=\frac{Q}{I A} \text {. }
$$

The Nusselt number for the forced turbulent convection in a rectangular cross-section duct can be approximated from the Dittus-Boelter correlation $\mathrm{Nu}=0.024 \mathrm{Re}^{0.8} \mathrm{Pr}^{0.4}$ as $\mathrm{Nu} \propto \mathrm{Re}^{0.8}$ and the heat transfer coefficient $h=\mathrm{Nu} k / D_{h}$ as $\mathrm{Nuk} /(2 \mathrm{H})$. Using (1) along with these approximations, the equation of the useful heat gain $Q$ can be expressed in the following form:

$$
Q=h A \Delta T \propto G^{0.8}\left(\frac{L}{H}\right)\left(\frac{1}{L}\right)^{0.2}(W L),
$$

where $\Delta T$ is the difference of the mean temperatures of the absorber plate and the air flowing through the collector duct.

Similarly the equations of the pressure loss $\delta p$ and pumping power $P$ for flow in a rectangular cross-section duct can be transformed as

$$
\begin{aligned}
\delta p & =\left(\frac{4 f L}{2 \rho D_{h}}\right) \dot{m}^{2} \\
& =\left(\frac{4 f L}{4 \rho H}\right) \times\left(\frac{W L G}{W H}\right)^{2}=\left(\frac{f G^{2}}{\rho}\right) \times\left(\frac{L}{H}\right)^{3}, \\
P & =\left(\frac{m}{\rho}\right) \delta p \\
& =\left(\frac{W L G}{\rho}\right) \times\left(\frac{f G^{2}}{\rho}\right) \times\left(\frac{L}{H}\right)^{3} \\
& =\left(\frac{f W L}{\rho^{2}}\right) \times G^{3} \times\left(\frac{L}{H}\right)^{3},
\end{aligned}
$$

where $m(=G A)$ is the mass flow rate of air. Using (1) and approximating friction factor $f$ from the Blasius equation $\left(f=0.0791 \mathrm{Re}^{-0.25}\right),(4 \mathrm{~b})$ can be further transformed to

$$
P \propto G^{2.75}\left(\frac{L}{H}\right)^{3}(W L) \times\left(\frac{1}{L}\right)^{0.25} .
$$

From the deductions presented above, it can be seen that the thermal efficiency of a solar air heater depends on the strength of the different modes of heat transfer, which in turn depend on the temperature of the absorber plate and glass cover, gap between absorber plate and glass cover, thickness of the cover, absorptivity of the absorber plate surface, wind velocity over the cover, sky and ambient temperatures, tilt of the collector, the conductivity and thickness of back and edge insulations, and so forth. The thermal efficiency of a solar air heater and the pumping power requirement are also a function of many design and operating parameters, namely, collector length, height of the duct and collector length to duct height ratio, mass flow rate per unit area of plate, convective heat transfer coefficient between the absorber plate and air flowing through the collector duct, friction factor, and so forth. The operating temperature of the air heater also depends on the solar insolation.

Studies on the effect of variation of the some of the abovementioned parameter on the solar air heater performance have been reported in the literature [2-5], which are either based on the empirical relations of top loss coefficient, sky temperature, and wind heat transfer coefficient or on the iterative solution of basic heat transfer equations with certain simplifying assumptions. However, none of these studies have reported the optimum value of some of the parameters, sensitivity of the collector performance to the uncertainties in the estimate of the wind heat transfer coefficient and sky temperature, and tolerances in the nominal values of design parameters. The specification of the permissible tolerances is essential from manufacturing aspect because of their effect on the manufacturing costs. This also helps in extending the performance assurance to the users.

Hence, the objective of the present work is to study the effect of the air heater performance to the variations of the above-mentioned parameters within a range, uncertainty in the estimate of some of them and the tolerances in the nominal values of the design parameters using a mathematical model, and also to extend recommendations regarding the manufacturing tolerances based on such analysis and the preferred values of some design parameters. 
It is to be noted that the deductions presented by (1) and (3)-(5a), (5b), and (5c) are approximate only and the actual dependence of the collector performance on variations in various design parameters can be seen only by an analysis using appropriate heat transfer and friction factor correlations for the asymmetrically heated solar air heater duct.

\section{Mathematical Model for Performance Evaluation of Solar Air Heater}

The performance of the air heater in the present study has been evaluated using a mathematical model presented for a smooth duct solar air heater by Karwa and Chauhan [6]. The model calculates the useful heat gain from the iterative solution of basic heat transfer equations of top loss $Q_{t}$ and equates the same with the heat transfer from the absorber plate to the air. The calculation of the back loss $Q_{b}$ is based on the iterative solution of the heat balance equations for the back surface of the collector. The edge loss $Q_{e}$ is estimated from the correlation of Klein [7].

The heat balance on the air heater, refer to Figure 1(b), gives the distribution of incident solar radiation $I$ into useful heat gain $Q$ and various heat losses. The useful heat gain can be expressed as

$$
Q=A I(\tau \alpha)-Q_{L}=A\left[I(\tau \alpha)-U_{L}\left(T_{p}-T_{a}\right)\right],
$$

where $(\tau \alpha)$ is the transmittance-absorptance product of the glass cover-absorber plate combination, $Q_{L}$ is total heat loss from the collector, which is a sum of the losses from top, back, and edge of the collector, and $U_{L}$ is the overall loss coefficient defined as

$$
U_{L}=\frac{Q_{L}}{A\left(T_{p}-T_{a}\right)},
$$

where $T_{p}$ is mean temperature of the absorber plate and $T_{a}$ is the ambient temperature.

The gained heat raises the temperature of the air flowing through the duct; hence

$$
Q=m c_{p}\left(T_{o}-T_{i}\right)=G A c_{p}\left(T_{o}-T_{i}\right) .
$$

Knowing the Nusselt number, the heat transfer coefficient $h$ between the absorber plate and the air is determined. The heat gain can then be expressed as

$$
Q=h A\left(T_{p}-T_{f m}\right),
$$

where $T_{f m}$ is the mean temperature of the air in the air heater duct.

2.1. Top Loss, $Q_{t}$. Heat transfer takes place by radiation and convection from the heated absorber plate at a mean temperature $T_{p}$ to the inner surface of the glass cover at temperature $T_{g i}$; hence

$$
Q_{t p g}=A\left[\frac{\sigma\left(T_{p}^{4}-T_{g i}^{4}\right)}{\left(1 / \varepsilon_{p}\right)+\left(1 / \varepsilon_{g}\right)-1}+h_{p g}\left(T_{p}-T_{g i}\right)\right] \text {, }
$$

where $\varepsilon_{p}$ and $\varepsilon_{g}$ are emissivities of the absorber plate and glass cover, respectively, and $h_{p-g}$ is convective heat transfer coefficient between the absorber plate and glass cover.

Heat flows by conduction from the inner surface at temperature $T_{g i}$ to the outer surface of the glass cover at temperature $T_{g o}$ through its thickness $\delta_{g}$. Hence,

$$
Q_{t g}=k_{g} A \frac{\left(T_{g i}-T_{g o}\right)}{\delta_{g}},
$$

where $k_{g}$ is the thermal conductivity of the glass.

From the outer surface of the glass cover at temperature $T_{g o}$, the heat is rejected by radiation to the sky at temperature $T_{\text {sky }}$ and by convection to the ambient air. Hence,

$$
Q_{\text {tgo }}=A\left[\sigma \varepsilon_{g}\left(T_{g o}^{4}-T_{\text {sky }}^{4}\right)+h_{w}\left(T_{g o}-T_{a}\right)\right],
$$

where $h_{w}$ is wind heat transfer coefficient, which is a function of the wind velocity.

When thermal equilibrium is established,

$$
Q_{t p g}=Q_{t g}=Q_{t g o}=Q_{t} .
$$

The uncertainty in the prediction of the wind heat transfer coefficient will have an impact on the accuracy of predicted thermal performance of a solar air heater. A discussion on the uncertainty has been presented in Appendix A.

The sky temperature $T_{\text {sky }}$ is difficult to estimate because it is a function of many parameters, such as atmospheric pollution and humidity [8]. Some researchers have assumed it to be equal to the ambient temperature because of the difficulty in making its correct estimate. Others have estimated the sky temperature by using different correlations. One such widely used relation due to Swinbank [9] for clear sky is

$$
T_{\text {sky }}=0.0552 T_{a}^{1.5},
$$

where $T_{\text {sky }}$ and $T_{a}$ are expressed in degree Kelvin. A discussion on the uncertainty associated with the estimate of the sky temperature has been presented in Appendix B.

For the estimate of the heat transfer coefficient $h_{p g}$ between the absorber plate and glass cover, the following three-region correlation of Buchberg et al. [10] has been used:

$$
\begin{gathered}
\mathrm{Nu}=1+1.446 \times\left(1-\frac{1708}{\mathrm{Ra}^{\prime}}\right)^{+}, \\
\text {for } 1708 \leq \mathrm{Ra}^{\prime} \leq 5900
\end{gathered}
$$

(the + bracket goes to zero when negative),

$$
\begin{gathered}
\mathrm{Nu}=0.229\left(\mathrm{Ra}^{\prime}\right)^{0.252}, \\
\text { for } 5900<\mathrm{Ra}^{\prime} \leq 9.23 \times 10^{4} \\
\mathrm{Nu}=0.157\left(\mathrm{Ra}^{\prime}\right)^{0.285}, \\
\text { for } 9.23 \times 10^{4}<\mathrm{Ra}^{\prime} \leq 10^{6},
\end{gathered}
$$

where $\beta$ is the slope of the collector with horizontal plane and $\mathrm{Ra}^{\prime}(=\mathrm{Ra} \cos \beta)$ is Rayleigh number for the inclined air 
layers in the gap, for a horizontally installed collector $\beta=0^{\circ}$. The Rayleigh number Ra for the natural convection between parallel plates (the glass cover and absorber plate) is given by

$$
\mathrm{Ra}=\left(\frac{g\left(T_{p}-T_{g i}\right) \delta_{p g}^{3}}{T_{m p g} \nu_{m p g}^{2}}\right) \operatorname{Pr},
$$

where $\delta_{p g}$ is the gap between the absorber plate and glass cover.

2.2. Back Loss, $Q_{b}$. Heat transfer rate $Q_{p b}$ by radiation from the heated absorber plate to the bottom surface of the duct at temperature $T_{b}$ is

$$
Q_{p b}=\frac{A \sigma\left(T_{p}^{4}-T_{b}^{4}\right)}{\left(1 / \varepsilon_{p i}\right)+\left(1 / \varepsilon_{b}\right)-1} .
$$

The absorber plate inner surface and duct bottom surface long wave emissivity values $\varepsilon_{p i}$ and $\varepsilon_{b}$, respectively, in (15) have been assumed to be 0.9 .

A part of the heat reaching bottom surface of the duct from the heated absorber plate is transferred to the air flowing through the duct at mean temperature $T_{f m}$ and the remaining is lost to the ambient through the back insulation (thickness $\delta$ and thermal conductivity $k_{i}$ ). Hence,

$$
Q_{b a}=h A\left(T_{b}-T_{f m}\right)+A\left(\frac{T_{b}-T_{a}}{\left(\delta / k_{i}\right)+\left(1 / h_{w}\right)}\right) \text {. }
$$

The heat balance for the duct bottom surface gives

$$
Q_{p b}=Q_{b a} \text {. }
$$

The temperature of the duct bottom surface $T_{b}$, estimated from the iterative solution of (17), gives the back loss as

$$
Q_{b}=\frac{A\left(T_{b}-T_{a}\right)}{\left(\delta / k_{i}\right)+\left(1 / h_{w}\right)} .
$$

The heat loss from the edge of the collector is a minor loss and has been estimated from the following empirical relation suggested by Klein [7]:

$$
Q_{e}=0.5 A_{\text {edge }}\left(T_{p}-T_{a}\right) \text {, }
$$

where $A_{\text {edge }}$ is the area of the edge of the air heater rejecting heat to the surroundings air.

The temperature of the heated air at the outlet of the air heater is calculated from

$$
T_{o}=T_{i}+\frac{Q}{m c_{p}} .
$$

Knowing the useful heat gain, the thermal efficiency $\eta$ of the solar air heater has been calculated from (2).

Niles et al. [11] have used the following equations to calculate the outlet air and mean plate temperatures when the solar air heater operates in an open loop mode (i.e., $T_{i}=T_{a}$ ):

$$
\begin{aligned}
& T_{o}=T_{a}+\frac{I(\tau \alpha) \xi}{U_{L}}, \\
& T_{p}=T_{i}+\frac{I(\tau \alpha)}{U_{L}} \times\left(1-\frac{G \xi c_{p}}{U_{L}}\right),
\end{aligned}
$$

where $\xi=1-\exp \left[-U_{L} /\left(G c_{p}\right)\left(1+U_{L} / h\right)^{-1}\right]=\left(F_{R} U_{L} / G c_{p}\right)$. Parameter $F_{R}$ is termed as heat removal factor and is given by

$$
F_{R}=\left(\frac{G c_{p}}{U_{L}}\right) \times\left[1-\exp \left(-\frac{F^{\prime} U_{L}}{G c_{p}}\right)\right] .
$$

Parameter $F^{\prime}$ in (22) is termed as efficiency factor. It is given by

$$
F^{\prime}=\left(1+\frac{U_{L}}{h}\right)^{-1}
$$

is

The mean air temperature equation in terms of $F_{R}$ and $F^{\prime}$

$$
T_{f m}=T_{i}+\frac{Q}{A U_{L} F_{R}}\left(1-\frac{F_{R}}{F^{\prime}}\right) .
$$

Equations (21) and (24) have been used for the crosscheck of the values of $T_{o}, T_{p}$, and $T_{f m}$ estimated earlier in the model.

2.3. Friction Factor and Heat Transfer Correlations for Rectangular Duct. For rectangular cross-section ducts, Karwa et al. [12] used the following correlation of Chen in [13] for the apparent (effective) friction factor for the laminar flow regime:

$$
f_{\text {app }}=\frac{24}{\operatorname{Re}}+\left(0.64+\frac{38}{\operatorname{Re}}\right) \frac{D_{h}}{4 L} .
$$

The last term in the equation accounts for the increase in the friction factor in the entrance region of the duct.

The heat transfer correlation from Hollands and Shewen [14] for the thermally developing laminar flow in the smooth rectangular section duct of solar air heaters with $L / H>125$ has been used, which is

$$
\mathrm{Nu}=5.385+0.148 \operatorname{Re}\left(\frac{H}{L}\right), \quad \text { for } \operatorname{Re}<2550 .
$$

The friction factor correlation used for transition to turbulent flow regime in rectangular cross-section smooth duct $(0 \leq H / W \leq 1)$ is [15]

$$
f=\left[1.0875-0.1125\left(\frac{H}{W}\right)\right] f_{o}
$$

where

$$
\begin{gathered}
f_{o}=0.0054+2.3 \times 10^{-8} \operatorname{Re}^{1.5}, \\
\text { for } 2100 \leq \operatorname{Re} \leq 3550, \\
f_{o}=1.28 \times 10^{-3}-0.1143 \mathrm{Re}^{-0.311}, \\
\text { for } 3550<\operatorname{Re} \leq 10^{7} .
\end{gathered}
$$

Bhatti and Shah [15] report an uncertainty of $\pm 5 \%$ in the predicted friction factors from the above correlation.

The apparent friction factor, to take account of the entrance effect, has been determined from the following 
relation for flat parallel plate duct in the turbulent flow regime [15]:

$$
f_{\text {app }}=f+0.0175\left(\frac{D_{h}}{L}\right)
$$

The Nusselt number correlations used for the transition and turbulent flow regimes from Hollands and Shewen [14] are

$$
\mathrm{Nu}=4.4 \times 10^{-4} \mathrm{Re}^{1.2}+9.37 \mathrm{Re}^{0.471}\left(\frac{H}{L}\right)
$$

for $2550 \leq \operatorname{Re} \leq 10^{4}$ (transition flow),

$$
\mathrm{Nu}=0.03 \operatorname{Re}^{0.74}+0.788 \operatorname{Re}^{0.74}\left(\frac{H}{L}\right)
$$

for $10^{4}<\operatorname{Re} \leq 10^{5}$ (early turbulent flow).

The laminar regime has been assumed in this model up to $\mathrm{Re}=2800$ as recommended by Karwa et al. [12] to limit the inconsistency of the predicted Nusselt number and friction factor values from correlations presented above to about $5 \%$ at the laminar-transition interface. The uncertainty of an order of 5-6\% in the predicted Nusselt number can be expected [12].

The pressure loss in the duct and the pumping power required to propel the air through the collector duct have been calculated by substituting the known value of friction factor $f_{\text {app }}$ in (4a) and (5a).

2.4. Thermohydraulic Performance Evaluation. Cortés and Piacentini [16] used effective thermal efficiency $\eta_{e}$ for the thermohydraulic performance evaluation, which is based on the net thermal energy output of a solar air heater considering the pumping power required to overcome the friction of the air heater duct. Since the operating cost of a collector depends on the pumping power spent, the effective efficiency is a logical criterion for the performance evaluation. The equation suggested by Cortés and Piacentini is

$$
\eta_{e}=\frac{Q-(P / C)}{I A}
$$

where $C$ is a conversion factor used for calculating equivalent thermal energy to obtain the pumping power. It is a product of the efficiencies of the fan, electric motor, transmission, and thermoelectric conversion. Based on the assumption of $60 \%$ efficiency of the blower-motor combination and 33\% efficiency of thermoelectric conversion process referred to the consumer point, factor $C$ has been taken as 0.2 in the present study.

The thermophysical properties of the air have been taken at the corresponding mean temperature $T_{m}=T_{f m}$ or $T_{m p g}$.
The following relations of these properties, obtained by correlating data from NBS (U.S.) [17], have been used:

$$
\begin{aligned}
c_{p} & =1006 \times\left(\frac{T_{m}}{293}\right)^{0.0155}, \\
k & =0.0257 \times\left(\frac{T_{m}}{293}\right)^{0.86}, \\
\mu & =1.81 \times 10^{-5}\left(\frac{T_{m}}{293}\right)^{0.735}, \\
\rho & =1.204 \times\left(\frac{T_{m}}{293}\right), \\
\operatorname{Pr} & =\frac{\mu c_{p}}{k} .
\end{aligned}
$$

Equations (4a) and (4b) to (32) constitute a nonlinear model for performance evaluation of the solar air heater. The model has been solved by following an iterative process depicted by the flow chart in Figure 2, which has been adapted from [6]. For the heat collection estimate, the iteration was terminated when the successive values of the plate and mean air temperatures differed by less than $0.05 \mathrm{~K}$. The iteration for the estimate of top loss has been continued till the heat loss estimates from the absorber plate to the glass cover and glass cover to the ambient; that is, $Q_{t p g}$ and $Q_{t g o}$ from (10a) and (10c), respectively, differed by less than $0.2 \%$.

2.5. Validation of the Mathematical Model. The mathematical model presented above has been validated by Karwa et al. [12] against the experimental data for a smooth duct flat plate solar air heater from an earlier work of the first author [18]. The standard deviations of the predicted values of thermal efficiency and pumping power from the experimental values of these parameters from [18] have been reported by Karwa et al. [12] to be $\pm 4.9 \%$ and $\pm 6.2 \%$, respectively. The model has also been validated by Karwa and Chitoshiya [19] with the results of their experimental study of thermal efficiency for smooth duct solar air heater.

\section{Range and Baseline Values of Various Parameters}

The range and baseline values of various design, ambient, and flow parameters for the present study are given in Tables 1 and 2, and the reasons for the selection of their values are presented below. The baseline values are the values that are optimum, preferred, average, or mostly used. The ambient temperature and estimated wind heat transfer coefficient values in Table 2 are the average values for Jodhpur, Rajasthan, India. The estimated wind heat transfer coefficient corresponds to the prevailing wind velocity; refer Appendix A.

For maximum summer availability of the solar insolation, collector slope $\beta$ with horizontal plane should be approximately $10^{\circ}-15^{\circ}$ less than latitude while, for the maximum winter availability, the slope should be approximately $10^{\circ}-$ $15^{\circ}$ more than latitude [22]. For maximum annual energy 


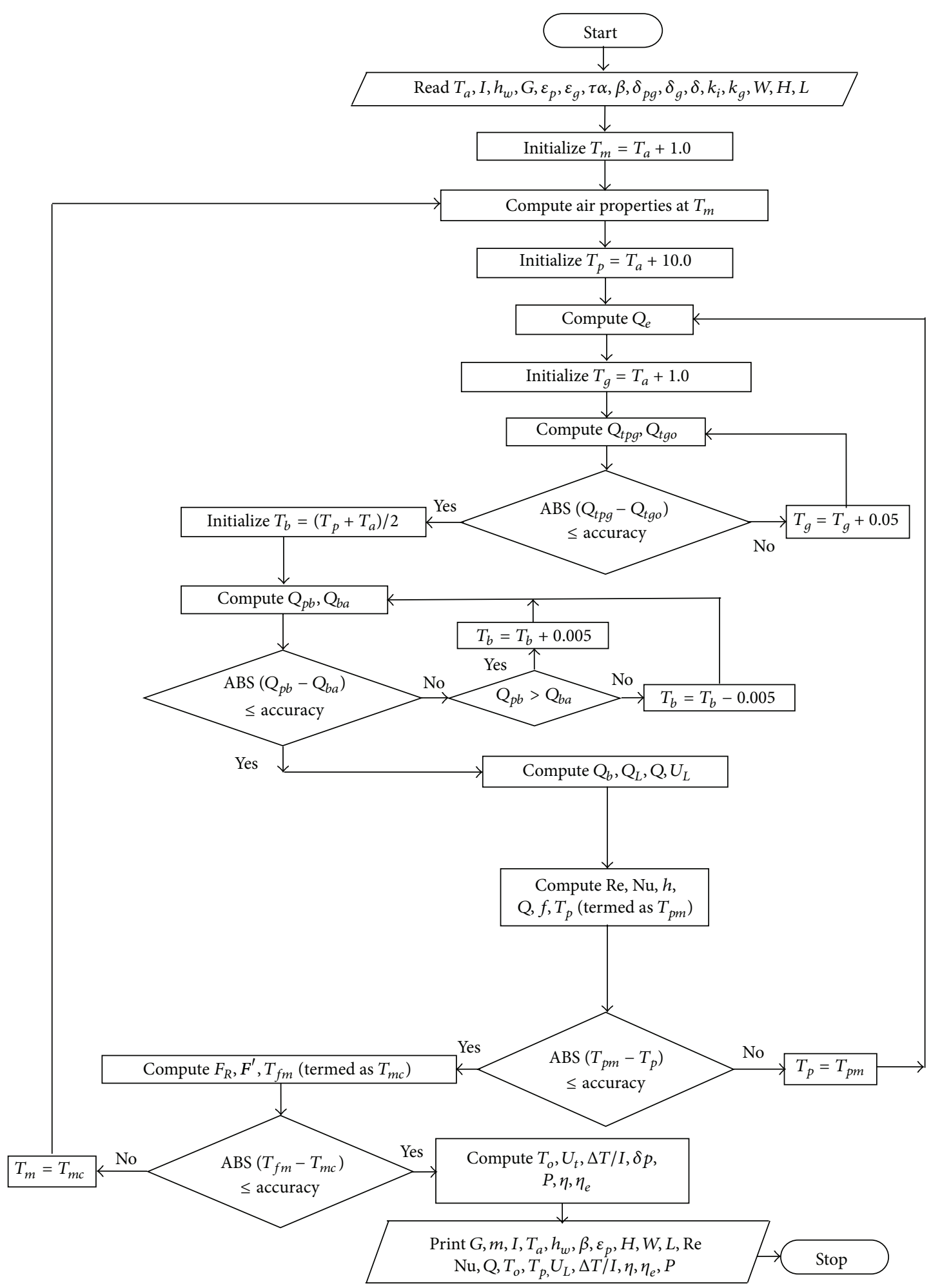

FIgURE 2: Flow chart depicting the iterative solution method for the mathematical model.

availability, the slope equal to the latitude is recommended. Thus, for the maximum collection of solar energy, the recommended value of the collector slope with horizontal plane for only winter operation at Jodhpur, Rajasthan, India (latitude $\approx$ $26^{\circ}$ ), is about $40^{\circ}$ and the same is $25^{\circ}$ (approximately equal to the latitude) for the year round optimum performance. When the collector is meant for summer operation only, the optimum value of the slope is about $10^{\circ}$, preferably horizontal for an ease of installation especially in the case of collector arrays. 
TABLE 1: Range and baseline values of various design parameters.

\begin{tabular}{|c|c|}
\hline Parameter & Values \\
\hline Transmittance-absorptance product for the absorber plate-glass cover combination, $\tau \alpha$ & 0.8 (single glass cover) \\
\hline Gap between the absorber plate and glass cover, $\delta_{p g}$ & $40-80 \mathrm{~mm}[10]$ \\
\hline Collector slope, $\beta$ & $\begin{array}{c}40^{\circ} \text { (winter) } \\
25^{\circ} \text { (year round operation), } \\
0^{\circ} \text { (summer) }\end{array}$ \\
\hline Insulation & Foamed polystyrene or glass wool \\
\hline Thermal conductivity of insulation material, $k_{i}$ & $0.037 \mathrm{Wm}^{-1} \mathrm{~K}^{-1}$ \\
\hline Insulation thickness, $\delta$ & $\geq 50 \mathrm{~mm}$ \\
\hline Glass thickness, $\delta_{g}$ & $\geq 4 \mathrm{~mm}$ \\
\hline Thermal conductivity of glass, $k_{g}$ & $0.78 \mathrm{Wm}^{-1} \mathrm{~K}^{-1}$ \\
\hline \multicolumn{2}{|l|}{ Long wave emissivity } \\
\hline Glass cover (window glass), $\varepsilon_{g}$ & $0.88[20]$ \\
\hline Absorber plate, $\varepsilon_{p}$ & 0.95 (black paint), 0.1 (selective coating) \\
\hline Duct surface & 0.9 \\
\hline Absorber plate (duct side) & $0.9[21]$ \\
\hline Length of the collector duct, $L$ & Baseline value $=2 \mathrm{~m}$ \\
\hline Duct height, $H$ & $5-20 \mathrm{~mm}$, baseline value $=10 \mathrm{~mm}$ \\
\hline Width of duct, $W$ & $1 \mathrm{~m}$ \\
\hline
\end{tabular}

TABLE 2: Ambient and flow parameters.

\begin{tabular}{lc}
\hline Parameter & Values \\
\hline Solar insolation, $I$ & $\begin{array}{c}\text { Range } 500-1000 \mathrm{Wm}^{-2} ; \\
\text { baseline: } 800 \mathrm{Wm}^{-2}\end{array}$ \\
$\begin{array}{l}\text { Mass flow rate per unit area of } \\
\text { absorber plate, } G\end{array}$ & $0.01-0.06 \mathrm{kgs}^{-1} \mathrm{~m}^{-2}$ \\
& $285 \mathrm{~K}$ (winter) $\pm 3 \mathrm{~K}$ \\
Ambient temperature, $T_{a}$ & $310 \mathrm{~K}$ (summer) $\pm 4 \mathrm{~K}$ \\
& Winter: range \\
& $9-12 \mathrm{Wm}^{-2} \mathrm{~K}^{-1}$, \\
Wind heat transfer coefficient, $h_{w}$ & baseline: $12 \mathrm{Wm}^{-2} \mathrm{~K}^{-1}$ \\
(Appendix A) & Summer: range \\
& $15-20 \mathrm{Wm}^{-2} \mathrm{~K}^{-1}$, \\
& baseline: $15 \mathrm{Wm}^{-2} \mathrm{~K}^{-1}$ \\
\hline
\end{tabular}

Open loop operation has been considered for which the inlet air temperature is taken as the ambient temperature.

The air mass flow rate per unit area of the absorber plate $G$ from thermal efficiency equation is

$$
G=\frac{\eta I}{c_{p}\left(T_{o}-T_{i}\right)} .
$$

Considering the extremities of the use of a solar air heater such as space heating or similar applications requiring air temperature rise of the order of $20^{\circ}$ to $50^{\circ} \mathrm{C}$ and crop drying (where even a $5-6^{\circ} \mathrm{C}$ temperature rise may be sufficient), thermal efficiency $\eta$ of the order of 40 to 65 per cent with transitional to turbulent flow, and a solar radiation intensity $I$ of 500 to $1000 \mathrm{Wm}^{-2}$, the mass flow rate per unit area of plate $G$ of 0.01 to $0.06 \mathrm{kgs}^{-1} \mathrm{~m}^{-2}$, as approximated from the above equation, has been used in the study.
From the approximate deductions presented in (5c) and (3), it can be seen that the pumping power requirement $P$ is proportional to $(1 / H)^{3}$ and $G^{2.75}$ while the energy collection rate $Q$ is proportional to $(1 / H)$ and $G^{0.8}$ for a given collector length and area. The results of the analysis on the study of the effect of variation of the duct height and flow rate on the thermal and effective efficiencies are presented in Figure 3. The thermal efficiency can be seen to increase with the decrease in the duct height and increase in the flow rate. With the decrease in the duct height, the pumping power increases rapidly and it may be a substantial part of the energy collection rate at high flow rates in low duct heights. The effect of duct height on the thermohydraulic performance, defined by effective efficiency based on the net energy gain, can be seen in Figure 3(b). For low duct heights, the effective efficiency increases with increase in the flow rate and can be seen to attain its maximum at a certain flow rate. For example, for $H=5 \mathrm{~mm}$, it takes its maximum at around $G$ $=0.026 \mathrm{kgs}^{-1} \mathrm{~m}^{-2}$ and then decreases rapidly at high flow rate. Hence, such collectors must not be employed for flow rates greater than about $0.025 \mathrm{kgs}^{-1} \mathrm{~m}^{-2}$. It can be inferred from the results presented in Figure 3(b) that a collector with duct height of $10 \mathrm{~mm}$ can be used practically over the whole range of the flow rate considered in the present study, with greater effective efficiency and only a marginal decrease in the effective efficiency for $G>0.052 \mathrm{kgs}^{-1} \mathrm{~m}^{-2}$ compared to the duct heights $>10 \mathrm{~mm}$. Hence, the duct height of $10 \mathrm{~mm}$ has been considered as baseline value in the present study.

From (1), it can be seen that, to avoid laminar flow at the low mass flow rates employed for the solar air heater applications as discussed above, the duct length must be kept greater than about $2 \mathrm{~m}$. However, because of the constraints of available size of plywood and glass sheets, and the ease of 


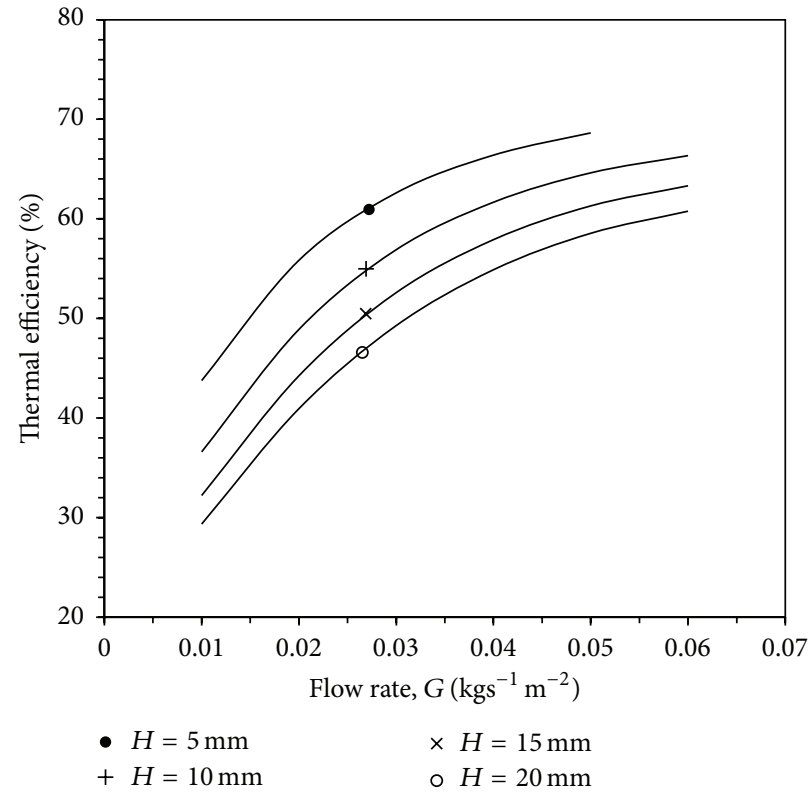

(a)

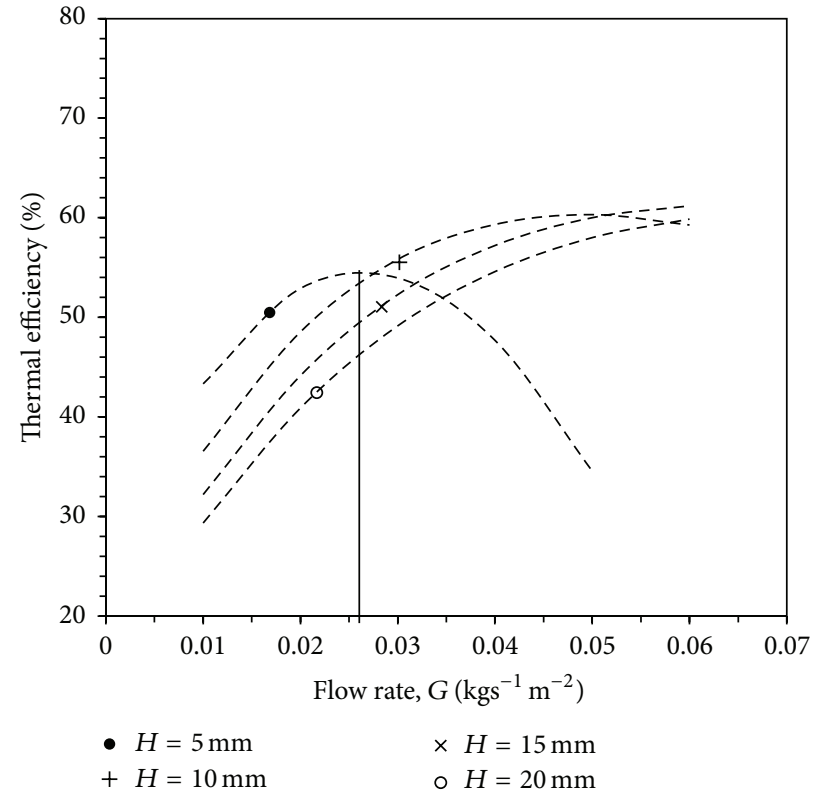

(b)

Figure 3: Effect of duct height on (a) thermal efficiency and (b) effective efficiency $\left(L=2 \mathrm{~m}, W=1 \mathrm{~m}, I=800 \mathrm{Wm}^{-2}, T_{a}=310 \mathrm{~K}, h_{w}=\right.$ $15 \mathrm{Wm}^{-2} \mathrm{~K}^{-1}$, and $\beta=0^{\circ}$ ).

installation and handling, the width $W$ of $1 \mathrm{~m}$ and length $L$ of $2 \mathrm{~m}$ are usually preferred for a collector module. Greater areas of solar collector surface are obtained by arranging such modules in series and parallel configurations in the array and increasing the duct height for greater lengths of the array to keep $L / H$ constant for equal pumping power constraint [1].

\section{Results and Discussion}

The effect of the variation in the ambient/environmental parameters (diurnal variation or uncertainty in the prediction) and tolerance in design parameters on the thermal efficiency, pumping power, and effective efficiency of the solar air heater has been studied by comparing the deviation of the performance from that at certain baseline values of these parameters given in Tables 1 and 2. In order to study the effect of the variation of these parameters, one parameter has been varied at a time.

4.1. Effect of Uncertainties and Variations of the Ambient Parameters $\left(h_{w}, T_{s k y}, T_{a}\right.$, and $\left.I\right)$. Various equations in the mathematical model of the solar air heater show the dependence of the solar air heater performance (thermal and effective efficiencies) on ambient parameters. The ambient temperature and solar insolation vary with the time of the day and season. A discussion on the uncertainties in the estimate and variations of the wind heat transfer coefficient and sky temperature has been presented in Appendices A and B, respectively.

4.1.1. Effect of Uncertainty in the Estimate of Wind Heat Transfer Coefficient. It has been shown in Appendix A that the estimated average value of summer wind heat transfer coefficient from different correlations varies from 12 to about $20 \mathrm{Wm}^{-2} \mathrm{~K}^{-1}$ at the prevailing wind velocity in Jodhpur. Hence, the baseline value of the wind heat transfer coefficient for the summer has been taken as $15 \mathrm{Wm}^{-2} \mathrm{~K}^{-1}$ with variation to $20 \mathrm{Wm}^{-2} \mathrm{~K}^{-1}$. In the case of collector with black-painted absorber plate, the thermal efficiency reduces by about $2.6 \%$ on increase in the wind heat transfer coefficient at the lowest flow rate $G$ of $0.01 \mathrm{kgs}^{-1} \mathrm{~m}^{2}$ of the absorber plate as seen in Figure 4. The reduction in the thermal efficiency is only $0.5 \%$ at the mass flow rate of $0.06 \mathrm{kgs}^{-1} \mathrm{~m}^{-2}$. In general, with the increase in the wind velocity, the convection heat loss from the glass cover increases. At low flow rates, the operating temperature of the absorber plate and hence that of the glass cover is high, and the heat loss due to the wind is higher. The analysis shows that the change in wind heat transfer coefficient from 15 to $20 \mathrm{Wm}^{-2} \mathrm{~K}^{-1}$ has a lower effect on the thermal efficiency when the absorber plate has selective coating $\left(\varepsilon_{p}=0.1\right)$; the reduction is about $1 \%$ at $G=0.01 \mathrm{kgs}^{-1} \mathrm{~m}^{-2}$ and negligible at $G=0.06 \mathrm{kgs}^{-1} \mathrm{~m}^{-2}$. Because of the reduced radiation heat flow from the absorber plate with selective coating to the glass cover, the glass cover temperature is lower and hence the effect of wind and its variation is less.

The baseline value of the wind heat transfer coefficient has been taken as $12 \mathrm{Wm}^{-2} \mathrm{~K}^{-1}$ for winter operation and reduced to $9 \mathrm{Wm}^{-2} \mathrm{~K}^{-1}$ for the study. With the reduction in the wind heat transfer coefficient, the thermal efficiency increases by $2.43 \%$ at the lowest flow rate of $G=0.01 \mathrm{kgs}^{-1} \mathrm{~m}^{-2}$ as shown in Figure 4 . The same has been found to be only about $0.2 \%$ at $G=0.06 \mathrm{kgs}^{-1} \mathrm{~m}^{-2}$ for the black-painted absorber plate 

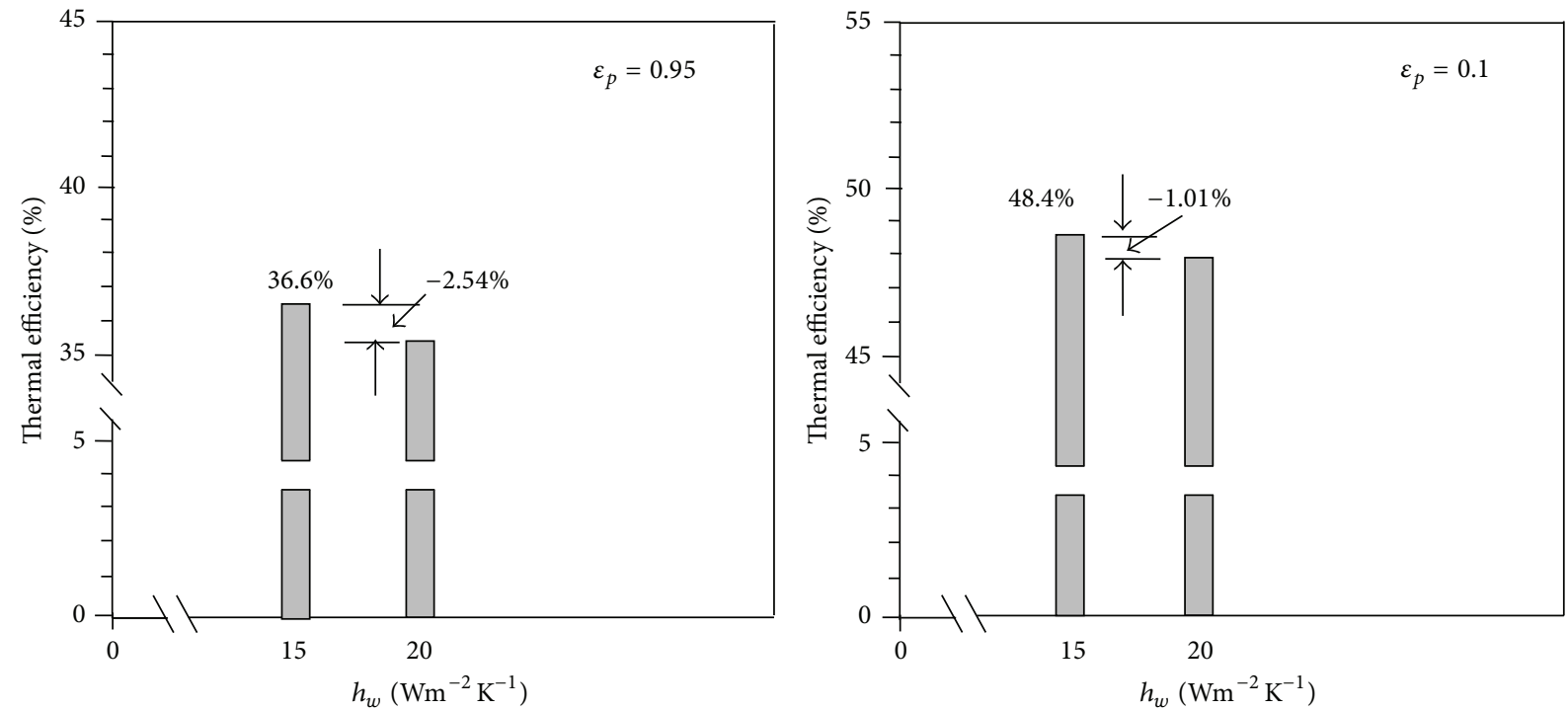

(a) $G=0.01 \mathrm{kgs}^{-1} \mathrm{~m}^{-2}$
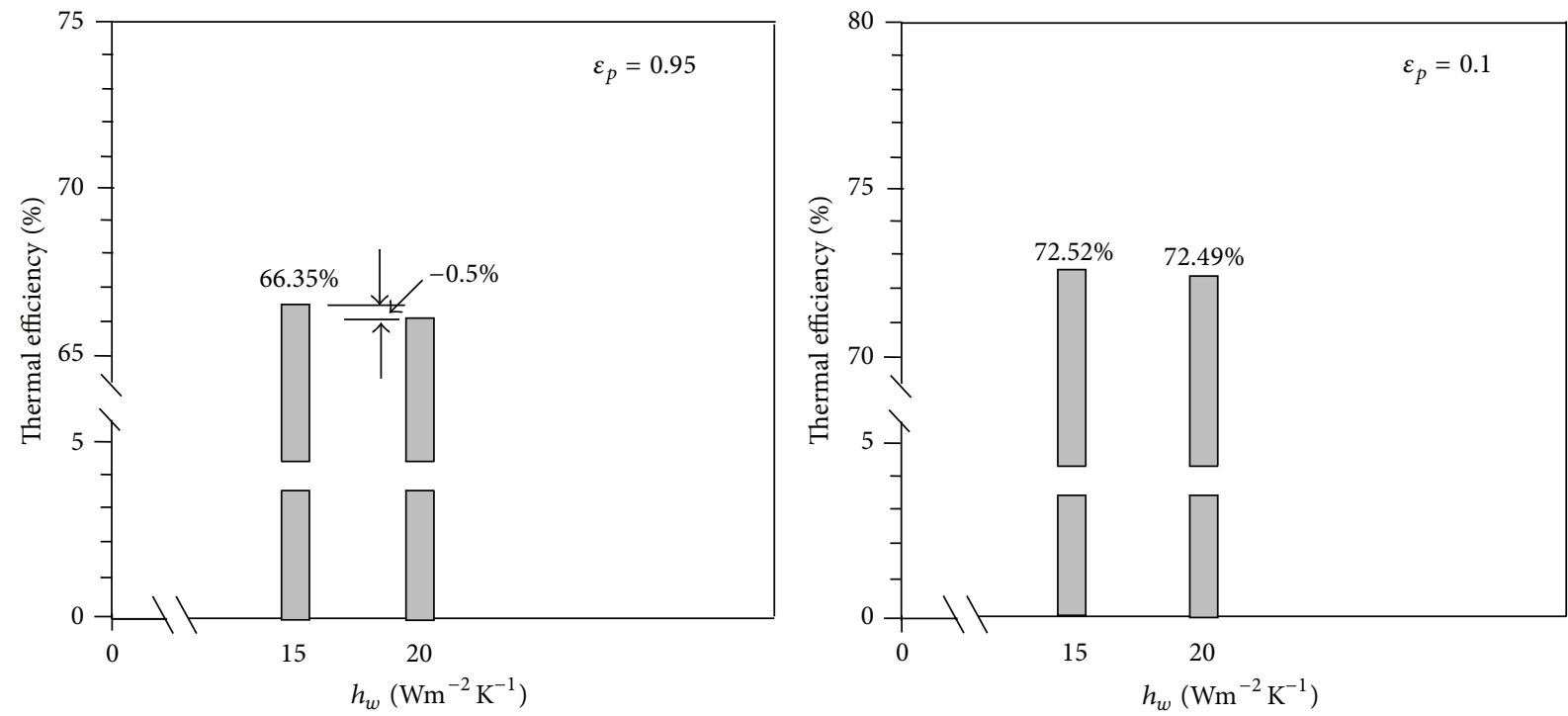

(b) $G=0.06 \mathrm{kgs}^{-1} \mathrm{~m}^{-2}$

FIGURE 4: Effect of change in wind heat transfer coefficient on thermal efficiency (summer operation).

$\left(\varepsilon_{p}=0.95\right)$. The corresponding values have been found to be $1 \%$ and negligible, respectively, when the absorber plate has selective coating.

The order of magnitude of the change in the effective efficiency due to change in the value of the wind heat transfer coefficient is the same because the pumping power requirement is only marginally affected.

4.1.2. Effect of Uncertainty in the Estimate of Sky Temperature. A discussion on the uncertainty associated with the estimate of the sky temperature has been given in Appendix B. Since, for a given ambient temperature, the sky temperature may vary because of the variation in the atmospheric humidity and pollution, the sky temperature has been varied by $\pm 5 \mathrm{~K}$ from the baseline value of sky temperature estimated from
Swinbank's relation. However, it may be noted that the uncertainty in the estimate of $T_{\text {sky }}$ can result in a greater variation in the sky temperature than considered here.

In general, with the increase in the sky temperature the thermal efficiency increases because of a lower radiation heat loss from the glass cover and vice versa; refer (10c). From Figure 5, it can be seen that, in the summer, a change in the sky temperature by $\pm 5 \mathrm{~K}$ affects the thermal efficiency by about $\pm 1.28 \%$ at the lowest flow rate for the absorber plate with black paint. The same is of the order of $\pm 0.8 \%$ at the lowest flow rate for absorber plate with selective coating. For both types of the absorbers, the effect has been seen to decrease with the increase in the flow rate. Since the change in the sky temperature has a negligible effect on the pumping power, the effect on the effective efficiency is of the same order 

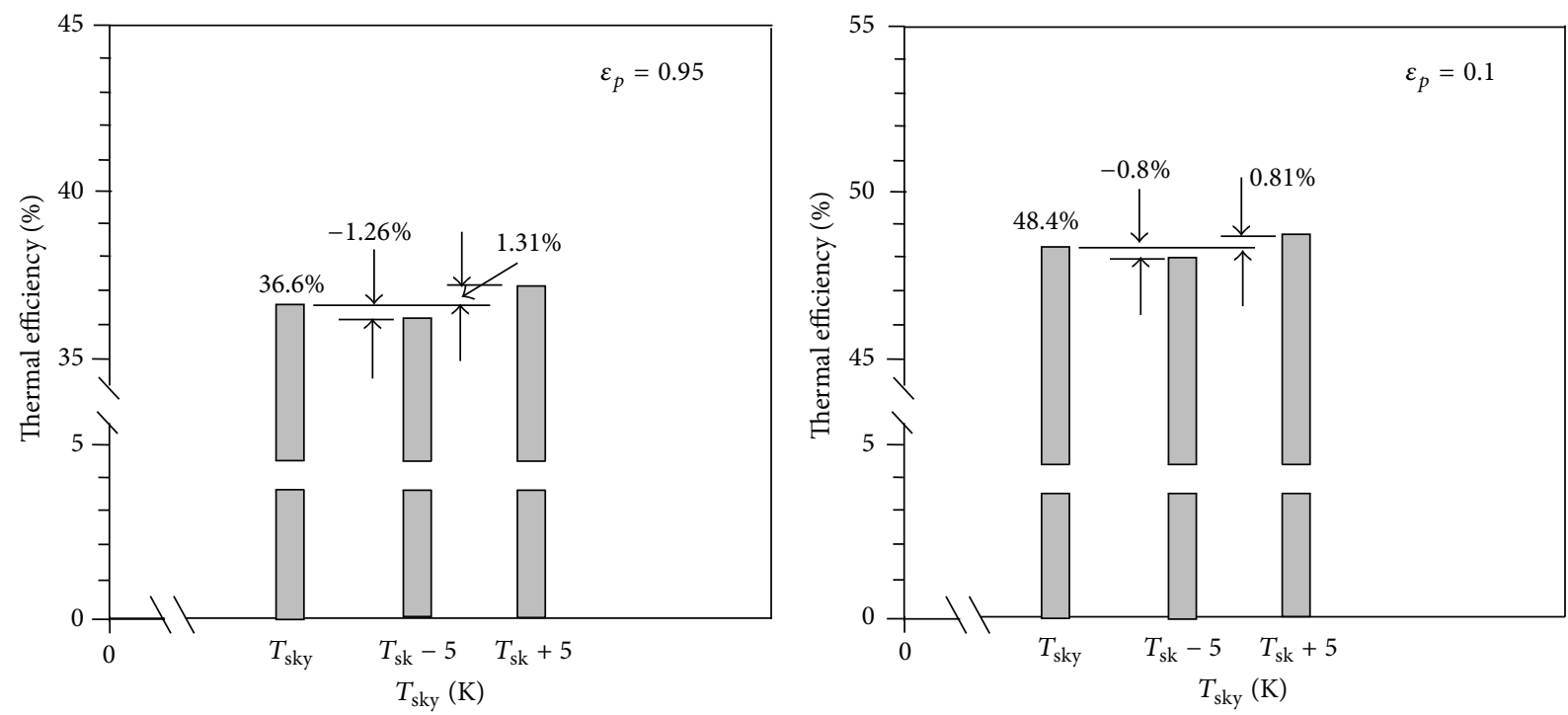

FIGURE 5: Effect of change in the sky temperature on thermal efficiency ( $G=0.01 \mathrm{kgs}^{-1} \mathrm{~m}^{-2}$; summer operation).

of magnitude. Further, it has been found that the trend of these effects on the thermal and effective efficiencies is the same but the effect is lower by about $25-40 \%$ when winter operation of the air heater was considered.

4.1.3. Effect of Variation of Ambient Temperature. The diurnal variation of ambient temperature in Jodhpur is from the minimum around $8 \mathrm{AM}$ to maximum around $4 \mathrm{PM}$ in the summer. Typical data shows that this variation is of the order of $6^{\circ} \mathrm{C}$ from $9 \mathrm{AM}$ to $4 \mathrm{PM}$ in June (the summer period) at Jodhpur. The corresponding variation in February is slightly higher (of the order of $8^{\circ} \mathrm{C}$ ). Hence, in the present study, the baseline temperature value of $310 \mathrm{~K}$, assumed for the summer operation, has been varied by $\pm 3 \mathrm{~K}$ while, for the winter operation, variation has been considered to be $\pm 4 \mathrm{~K}$ from a mean ambient temperature of $285 \mathrm{~K}$ as the baseline value.

The analysis shows that the effect on the thermal efficiency of the air heater with black-painted absorber plate surface is of the order of $\pm 0.16 \%$ and $\pm 0.4 \%$ for the summer and winter variations in the ambient temperature, respectively, at the lowest flow rate of the study; a decrease in the temperature has a positive effect on the thermal efficiency. The effect is found to be less than about $0.1 \%$ at the highest flow rate of $0.6 \mathrm{kgs}^{-1} \mathrm{~m}^{-2}$, negligible for the collector with selective coating on the absorber plate surface. This is because of the fact that the operating temperature of the collector decreases with the increase in the air mass flow rate and the glass cover temperature of the collector with selective coating is lower than that of the black-painted one.

It must be noted that the diurnal changes in the ambient temperature and solar radiation intensity occur simultaneously. But for clarity, one parameter has been changed at a time. The effect of variation of solar radiation intensity is presented in the next section.
4.1.4. Effect of Variation in the Solar Radiation Intensity. The solar radiation intensity $I$ has been varied from the minimum of $500 \mathrm{Wm}^{-2}$ to the maximum of $1000 \mathrm{Wm}^{-2}$ from the baseline value of $800 \mathrm{Wm}^{-2}$; the assumed minimum and maximum values occur at around $9 \mathrm{AM}$ and 3.30 PM and at the solar noon (12.20 PM for Jodhpur), respectively.

The results of the analysis are presented in Table 3, wherein it can be seen that the effect of variation in the solar insolation from 500 to $1000 \mathrm{Wm}^{-2}$ on the thermal efficiency is -1.69 to $0.98 \%$ in the winter and -1.31 to $1.64 \%$ in the summer conditions. The effect on the effective efficiency is of the same order of magnitude at the lowest flow rate of the study because the pumping power is only a small fraction of the energy collection rate. Since the pumping power $P$, which is proportional to $G^{2.75}$, increases rapidly with the flow rate, the net gain and hence the effective efficiency is adversely affected because of the low energy collection rates when the solar radiation intensity is low. For example, at the highest flow rate of the study, the effective efficiency reduces by -6.3 to $-8.4 \%$ when solar radiation intensity $I$ is reduced from $800 \mathrm{Wm}^{-2}$ to $500 \mathrm{Wm}^{-2}$. The same is increased by $1.4-2.46 \%$ at $I=1000 \mathrm{Wm}^{-2}$ because of the increased energy collection rate. It must be noted that with the decrease in the solar insolation, the mass flow may be decreased to maintain a nearly constant outlet temperature and hence the effect on the effective efficiency will be lower than mentioned [23].

It is to mention that, in the case of the solar air heater with $25^{\circ}$ slope used for the year round performance, the trends and magnitude of the effects of the variation or uncertainties of the above-mentioned parameters on the thermal and effective efficiencies have been found to be practically of the same order of magnitude as reported above for the collector meant for summer or winter operation only. 
TABLE 3: Effect of change of solar insolation $I$ on thermal and effective efficiencies $(L=2 \mathrm{~m}, H=10 \mathrm{~mm}$, and $W=1 \mathrm{~m})$.

\begin{tabular}{|c|c|c|c|c|c|c|c|c|}
\hline \multirow{2}{*}{$G\left(\mathrm{kgs}^{-1} \mathrm{~m}^{-2}\right)$} & \multirow{2}{*}{ Baseline value } & \multirow{2}{*}{$\varepsilon_{p}$} & \multicolumn{3}{|c|}{ Winter $\left(T_{a}=285 \mathrm{~K}, h_{w}=12 \mathrm{Wm}^{-2} \mathrm{~K}^{-1}, \beta=40^{\circ}\right)$} & \multicolumn{3}{|c|}{ Summer $\left(T_{a}=310 \mathrm{~K}, h_{w}=15 \mathrm{Wm}^{-2} \mathrm{~K}^{-1}, \beta=0^{\circ}\right)$} \\
\hline & & & $I\left(\mathrm{Wm}^{-2}\right)$ & $\Delta \eta / \eta(\%)$ & $\Delta \eta_{e} / \eta_{e}(\%)$ & $I\left(\mathrm{Wm}^{-2}\right)$ & $\Delta \eta / \eta(\%)$ & $\Delta \eta_{e} / \eta_{e}(\%)$ \\
\hline 0.01 & 800 & 0.95 & $\begin{array}{c}500 \\
1000\end{array}$ & $\begin{array}{c}0.7 \\
-1.04\end{array}$ & $\begin{array}{c}0.63 \\
-1.03\end{array}$ & $\begin{array}{c}500 \\
1000\end{array}$ & $\begin{array}{l}1.64 \\
-1.31\end{array}$ & $\begin{array}{c}1.64 \\
-1.25\end{array}$ \\
\hline 0.06 & 800 & 0.95 & $\begin{array}{l}500 \\
1000\end{array}$ & $\begin{array}{c}-1.69 \\
0.48\end{array}$ & $\begin{array}{c}-8.1 \\
2.4\end{array}$ & $\begin{array}{l}500 \\
1000\end{array}$ & $\begin{array}{c}-0.74 \\
0.14\end{array}$ & $\begin{array}{c}-8.43 \\
2.46\end{array}$ \\
\hline 0.01 & 800 & 0.1 & $\begin{array}{c}500 \\
1000\end{array}$ & $\begin{array}{c}0.98 \\
-0.68\end{array}$ & $\begin{array}{c}0.94 \\
-0.64\end{array}$ & $\begin{array}{c}500 \\
1000\end{array}$ & $\begin{array}{c}1.88 \\
-0.99\end{array}$ & $\begin{array}{c}1.8 \\
-0.98\end{array}$ \\
\hline 0.06 & 800 & 0.1 & $\begin{array}{c}500 \\
1000\end{array}$ & $\begin{array}{c}-0.67 \\
0.14\end{array}$ & $\begin{array}{c}-6.27 \\
1.87\end{array}$ & $\begin{array}{c}500 \\
1000\end{array}$ & $\begin{array}{c}-0.06 \\
0.01\end{array}$ & $\begin{array}{c}-6.77 \\
1.42\end{array}$ \\
\hline
\end{tabular}

\subsection{Effect of the Uncertainties in Heat Transfer Coefficient and} Friction Factor. Karwa et al. [1] found from the sensitivity analysis that a $1 \%$ change in the heat transfer coefficient for the flow of air through the collector duct affects the thermal efficiency by $0.15-0.35 \%$ depending on the flow rate. Thus a $5 \%$ uncertainty in the estimate of the heat transfer coefficient will affect the thermal efficiency by about $0.75-1.65 \%$. The uncertainty in the estimate of the friction factor does not affect the energy collection rate and hence has no effect on the predicted thermal efficiency. From (4b) and (5b), it can be seen that the change in the pressure drop and the pumping power will be of the same magnitude as the uncertainty in the friction factor.

4.3. Sensitivity of the Solar Air Heater Performance to the Tolerances in Design Parameters. The sensitivity of the solar air heater performance to the tolerance of different design parameters has been studied by varying one parameter at a time from its baseline value and determining the deviation of the performance from the performance at the baseline values of these parameters. The results of the analysis are being presented and discussed below.

4.3.1. Effect of Tolerance in Height of the Duct. The baseline value of the height of the duct in the analysis has been assumed to be $10 \mathrm{~mm}$ for a collector length of $2 \mathrm{~m}$ giving $\mathrm{L} / \mathrm{H}$ ratio of 200. The manufacturing tolerance in the duct height has been assumed to be $\pm 1 \mathrm{~mm}$ for the analysis.

Dependence of heat collection rate of a solar air heater on the duct height $H$ can be seen from (3). Figure 6(a) depicts the sensitivity of the collector performance to the variation in the duct height when it is operating at the lowest flow rate in the winter. It can be seen that the thermal efficiency increases by about $3 \%$ as the height is decreased from 10 to $9 \mathrm{~mm}$. The increase in the height from 10 to $11 \mathrm{~mm}$ decreases thermal efficiency by about $2.7 \%$. Similar trends have been found for the absorber plate with selective coating but such air heaters are found to be about $20 \%$ less sensitive to the variation in the duct height as compared to the collector with blackpainted absorber. For the summer operation, the trend has been found to be similar but there is about $10 \%$ greater effect on the thermal efficiency. For the year round operation, the trends and the magnitudes of the changes have been found to be of the same order of magnitude.
The simplified deduction in (5c) shows strong dependence of pumping power on the duct height and air mass flow rate $G$. Since the pumping power is only a small fraction of the heat collection rate at the lowest flow rate of the study, the trend of change in the effective efficiency in Figure 6(a) follows that for the thermal efficiency. At higher flow rates, the pumping power is a substantial part of the heat collection rate. It can be seen in Figure 6(b) that at the flow rate of $0.06 \mathrm{kgs}^{-1} \mathrm{~m}^{-2}$ the change in the duct height affects the effective efficiency significantly; the decrease in the duct height has greater affect than the increase in the height.

From the results, it can be recommended that the tolerance in the duct height is a critical factor and it must be as small as possible especially for the collectors operating at high flow rates, not exceeding $\pm 1 \mathrm{~mm}$. For other duct heights, the tolerance may be proportionally changed.

4.3.2. Effect of Uncertainty in Value of Plate Absorptivity. The solar radiation reaches the absorber plate after transmission through the glass cover. The transmissivity $\tau$ of the window glass is about 0.85 and the solar energy absorbed by the absorber plate is $I(\tau \alpha)$, where $\alpha$ is the absorptivity of the absorber plate surface. Thus a $1 \%$ decrease in the absorptivity value will reduce the input energy to the absorber plate by about $0.85 \%(=\tau \alpha)$.

Surface roughness significantly affects the absorptivity and emissivity of metal surfaces $[24,25]$. In the case of flat black-painted absorber plate surface, the surface of the plate is first roughened and then painted black to achieve a high absorptivity value.

The baseline value of the absorptivity of the flat blackpainted absorber plate has been assumed to be 0.95 in the analysis (= the baseline value of the emissivity for the surface) and the effect of a change in the absorptivity from 0.95 to 0.9 has been studied here.

From the results of the analysis presented in Figure 7 for the winter operation, it can be seen that the thermal efficiency is reduced by $4.2-5.06 \%$ for the $5.26 \%$ reduction $(0.95$ to 0.9 ) in the absorptivity of the plate surface. For the summer operation, a slightly lower effect has been found. The change in the plate absorptivity does not affect the pumping power requirement.

It can be concluded that the plate emissivity is an important parameter and due care must be exercised in 

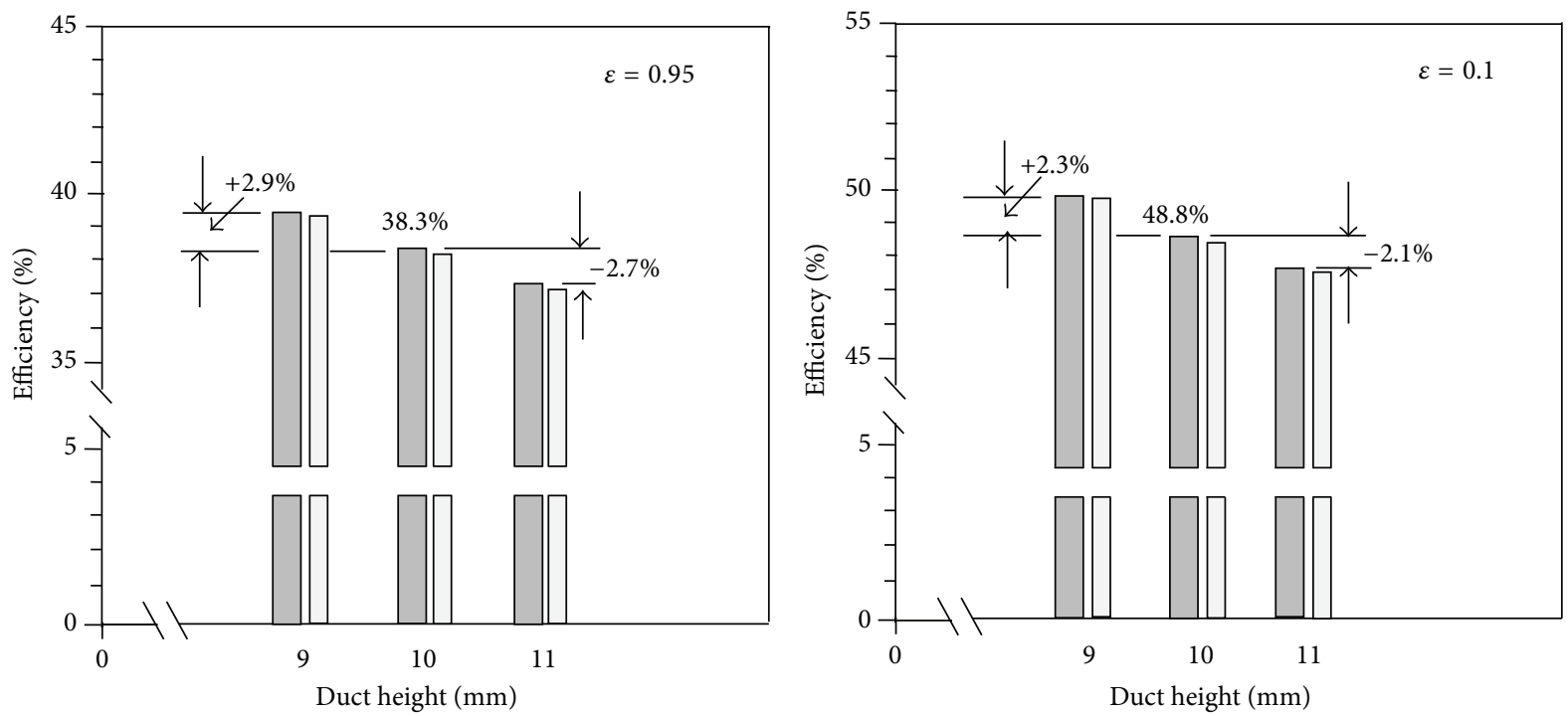

(a) $G=0.01 \mathrm{kgs}^{-1} \mathrm{~m}^{-2}$; only deviations for thermal efficiency marked
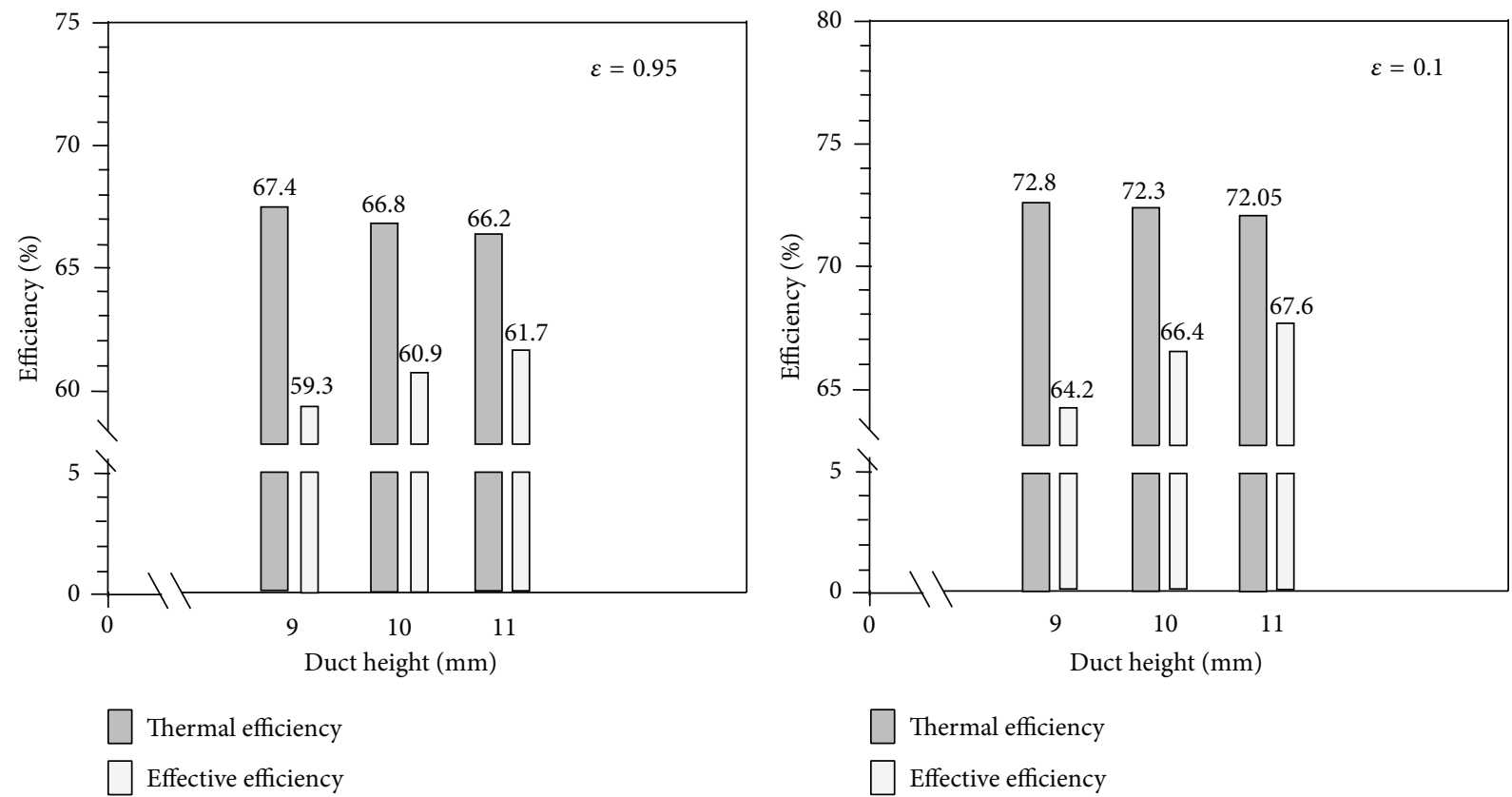

Thermal efficiency

Effective efficiency

(b) $G=0.06 \mathrm{kgs}^{-1} \mathrm{~m}^{-2}$

Figure 6: Effect of tolerance in duct height on thermal and effective efficiencies (winter operation).

the preparation of the absorber plate surface to achieve the desired value of absorptivity for the solar radiation.

4.3.3. Effect of Roughness of the Duct Surface. The solar air heater duct is made of plywood on the three sides, which are adiabatic sides of the duct. The fourth broad side (sun facing side) of the duct carries a smooth surfaced steel or aluminium absorber plate. Thus the roughness of the adiabatic sides of the duct will not contribute to the heat transfer enhancement though it will lead to an increase in the pressure drop and hence in the pumping power required due to a higher friction factor for such surfaces when the flow is in transitional or turbulent regime. Therefore, it is recommended that the air side plywood surface of the duct should be smooth for the air heaters operating in transitional or turbulent flow conditions.

4.3.4. Effect of Tolerance in Gap $\delta_{p g}$ between Absorber Plate and Glass Cover. The heat transfers from the heated absorber plate to the glass cover by convection and radiation. The convection heat transfer coefficient is a function of the gap between the absorber plate and glass cover. In the present study, the gap has been varied from $30 \mathrm{~mm}$ to $70 \mathrm{~mm}$ in steps of $10 \mathrm{~mm}$, where the gap value of $40 \mathrm{~mm}$ has been considered as the baseline value. From the plot in Figure 8 for winter 

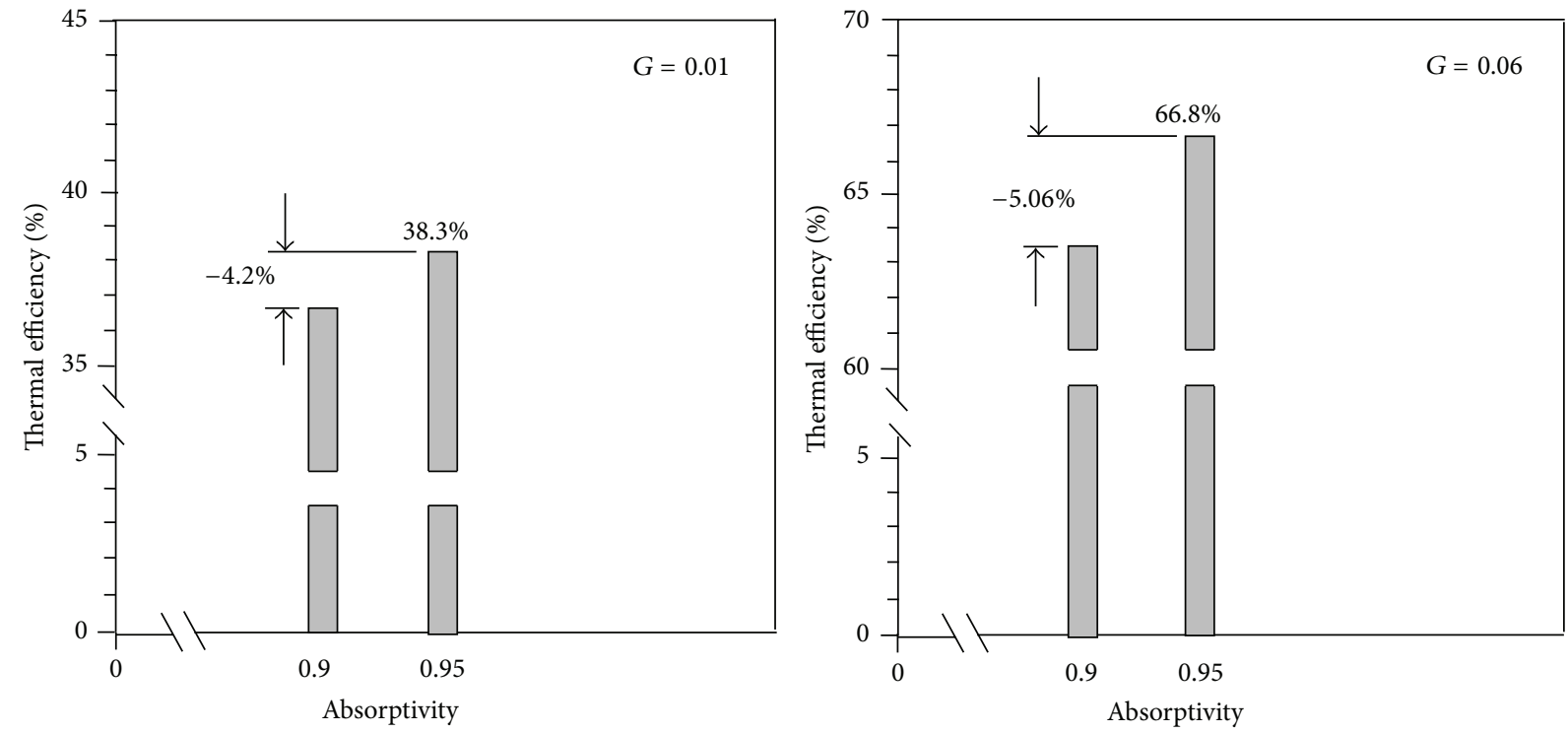

FIGURE 7: Effect of change in absorptivity (emissivity) of black-painted absorber plate on thermal efficiency (winter operation).

operation and at the lowest flow rate of the study, it can be seen that for a decrease in the gap by $10 \mathrm{~mm}$ from baseline value of $40 \mathrm{~mm}$, the collector efficiency decreases by about $0.6 \%$, while the gain for the increase in the gap from $40 \mathrm{~mm}$ to $70 \mathrm{~mm}$ is about $0.5 \%$. At the flow rate of $0.06 \mathrm{kgs}^{-1} \mathrm{~m}^{-2}$, the corresponding changes in the thermal efficiency values have been found to be only 0.22 and $0.24 \%$, respectively. A higher effect at the low flow rates happens because of the high operating temperature of the collector at such flow rates. Thus it can be seen that a noticeable gain in the thermal efficiency can be achieved only by a significant increase in the gap from the baseline value of $40 \mathrm{~mm}$. An increase in the gap will increase edge thickness of the collector and hence will increase the bulk and initial cost of the collector. Therefore, it is recommended that, to keep the collector bulk at a minimum, this gap for optimum performance may be kept at $40 \mathrm{~mm}$ and a liberal tolerance on the positive side from $40 \mathrm{~mm}$ may be permitted; a liberal tolerance will reduce the fabrication cost of the collector.

4.3.5. Effect of Variation in the Collector Slope. As discussed earlier, the values of collector slope $\beta$ has been considered to be $0^{\circ}$ (horizontal; for the ease of installation and summer operation), $40^{\circ}$ (winter operation), or $25^{\circ}$ (equal to the latitude of Jodhpur for year round optimum performance).

The convection heat transfer coefficient $h_{p g}$ for the heat transfer between the heated absorber plate and glass cover depends on the collector slope. The sensitivity analysis shows that a $\pm 5^{\circ}$ change in slope of the collector practically does not affect the thermal performance for the horizontally installed collector considered for the summer operation in the present study. But for the collector considered for the winter operation, in general, the thermal performance improves by $0.075-$ $0.47 \%$ with the increase in the slope from the baseline value of $40^{\circ}$ due to a lower value of the heat transfer coefficient $h_{p g}$. The maximum increase has been found for the collector with

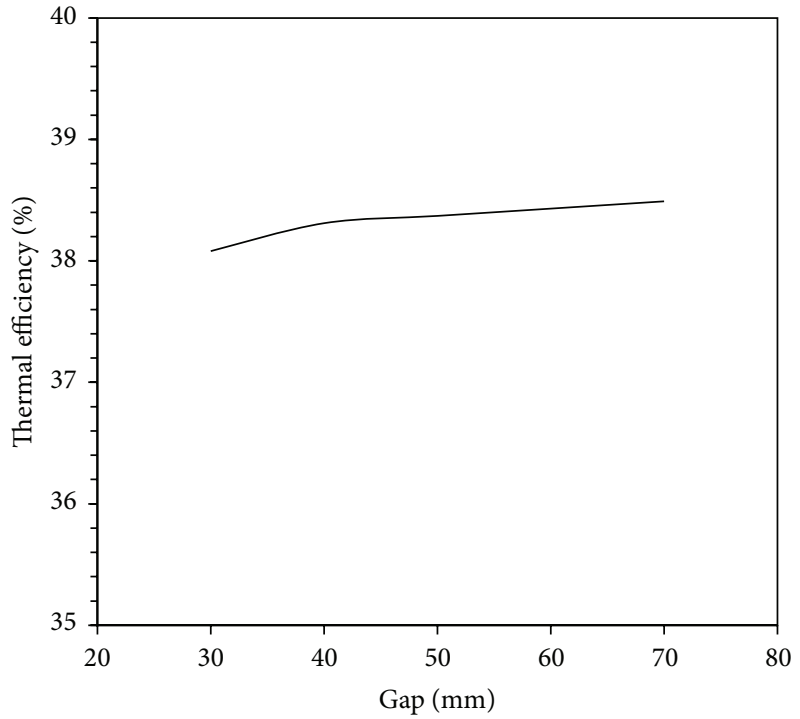

FIGURE 8: Effect of change in gap between absorber plate and glass cover on thermal efficiency (winter operation, $\varepsilon_{p}=0.95, G=$ $\left.0.01 \mathrm{kgs}^{-1} \mathrm{~m}^{-2}\right)$.

selective coating when operating at the lowest flow rate of the study.

The performance of a solar collector is also affected by its angle of slope with the horizontal plane because of the fact that the slope angle changes the solar radiation reaching the surface of the collector [26]. The solar insolation on the collector plane decreases approximately by a factor of $\cos 5^{\circ}$, that is, about $0.4 \%$ when the collector slope is changed by $5^{\circ}$. A decrease in the slope has negative effect from both of the above counts.

It can be concluded from the above discussion that the collector slope must not be less than the baseline value and it 
is also better to limit the variation (tolerance) on the positive side of the baseline value to the minimum possible. However, too small tolerance will increase the installation cost. Hence, the tolerance in the installation of the collector for winter operation is recommended as $\beta_{-0^{\circ}}^{+3^{\circ}}$.

The recommended value of the collector slope is $25^{\circ}$ with horizontal plane for the year round optimum performance. If the slope happens to be greater than $25^{\circ}$, it will be beneficial in winter while a smaller than $25^{\circ}$ slope will be beneficial in summer because of the increased solar radiation on the collector plane. Hence, for the collectors meant for year round application, an equal tolerance of $3^{\circ}$ on both sides may be recommended.

4.3.6. Effect of Tolerance in Glass Thickness. In the baseline design, the glass thickness has been assumed to be $4 \mathrm{~mm}$. An increase in thickness of the glass by $1 \mathrm{~mm}$ has been considered here. The analysis shows that the thermal efficiency increases with the increase in the thickness because of the increased conductive resistance of the glass to the top loss; $1 \mathrm{~mm}$ increase in the thickness has been found to improve the thermal efficiency by $0.11-0.44 \%$ (maximum at the flow rate of $0.01 \mathrm{kgs}^{-1} \mathrm{~m}^{-2}$ for the collector with selective coating) when the transmissivity of the glass is assumed to be not affected by the change in its thickness. The gain is still lower at the high flow rates, $0.11-0.14 \%$ only at the flow rate of $0.06 \mathrm{kgs}^{-1} \mathrm{~m}^{-2}$. The operating temperature of the absorber plate is low at high air mass flow rates, and the heat transfer by radiation to the glass cover is lower for the absorber plate with selective coating. Hence, for both of these conditions, the thermal efficiency has been seen to be less affected by the change in the glass thickness.

It is to note that, in the case of a window glass, doubling the thickness from about $3 \mathrm{~mm}$ to $6 \mathrm{~mm}$ increases the absorption of the total solar radiation by $6 \%$ [27]. Thus, the increase in the absorptivity of the glass with an increase in the thickness will lead to a reduction in the transmission of the solar radiation to the absorber plate and thus the net gain will not be positive. Too thin a glass may not be structurally strong. Hence, it can be concluded that the thickness of the glass should be as minimum as possible from transmissivity consideration but it should have sufficient strength.

\subsubsection{Effect of Variation in Back and Edge Insulation Thickness.} The gain with the increase in the thickness of the insulation from 50 to $65 \mathrm{~mm}$ is found to be higher at the low flow rates because of the high operating temperature of the collector at such flow rates. Typically for the winter operation, this gain is $0.57 \%$ at $G=0.01 \mathrm{kgs}^{-1} \mathrm{~m}^{-2}$ for the black-painted collector, only $0.12 \%$ at $G=0.06 \mathrm{kgs}^{-1} \mathrm{~m}^{-2}$. The corresponding values for the collector with absorber having selective coating on the surface are $0.82 \%$ and $0.14 \%$, respectively. In the case of absorber with selective coating, the radiation heat loss from the absorber plate to the glass cover reduces and the collector absorber plate and the air in the duct both are at a higher temperature. Hence, the increase in the insulation thickness on the back side is more beneficial.
It is to be noted that the reduction in the thermal efficiency for the reduction in the thickness of the insulation from $50 \mathrm{~mm}$ to $35 \mathrm{~mm}$ has been found to be $0.99 \%$ and $1.39 \%$ for the black-painted absorber and selective coating on the plate surface, respectively, at the lowest flow rate of the study as compared to $0.24 \%$ and $0.25 \%$, respectively, at the high flow rates.

It is evident that, for a collector operating with low flow rates, the insulation thickness should not be less than $50 \mathrm{~mm}$. An increase in the thickness to $65 \mathrm{~mm}$ is preferable because the gain (though small) is at a marginal extra cost only since the cost of the insulation material is usually a small fraction of the total cost of the collector. For the applications involving high flow rates, insulation thickness of $50 \mathrm{~mm}$ may be used. In general, it can be inferred that a liberal tolerance or variation in the insulation thickness on the positive side of $50 \mathrm{~mm}$ may be permitted.

\section{Conclusions}

Analysis has been carried out using a mathematical model of the solar air heater to study the effects of the uncertainty in the estimate, variation in a range, or tolerance in ambient and design parameters on the thermohydraulic performance of the air heater. The effects have been studied by comparing the deviation of the performance with that at certain baseline values of these parameters. The tolerances have been specified such that the variations in the nominal values of the design parameters do not affect the performance significantly. The main conclusions are as follows.

(1) For the range of flow rates of the study, a duct height of $10 \mathrm{~mm}$ is preferred from the thermohydraulic consideration.

(2) The greatest effect on thermal and effective efficiencies (of the order of $2.5 \%$ ) of black-painted absorber plate (emissivity $=0.95$ ) due to the variation in the wind heat transfer coefficient is at the lowest flow rate of the study.

(3) The effect of variation of $\pm 5 \mathrm{~K}$ in the sky temperature is of the order of $\pm 1.25 \%$ on the thermal and effective efficiencies for the absorber plate with emissivity of 0.95 .

(4) The effect of variation in the solar insolation from 500 to $1000 \mathrm{Wm}^{-2}$ on the thermal efficiency is about -1.5 to $1.3 \%$. At the higher flow rates, the effective efficiency is significantly affected when solar insolation decreases.

(5) In general, the effects of the variation in the ambient parameters are lower at high flow rates and for the absorber plate with selective coating.

(6) The tolerance in the duct height strongly affects the thermohydraulic performance; hence it must be as small as possible, not exceeding $\pm 1 \mathrm{~mm}$ for the $10 \mathrm{~mm}$ duct height. 
(7) The thermal performance is reduced by the same order of magnitude as is the reduction in the absorptivity of the absorber plate. This requires a careful preparation of the solar radiation absorbing plate surface.

(8) For the air heater operating with transitional or turbulent flow condition, the air side plywood surface should be smooth.

(9) The gap between the absorber plate and glass cover for the optimum performance may be kept at $40-50 \mathrm{~mm}$; a liberal tolerance on the positive side of $40 \mathrm{~mm}$ may be permitted.

(10) Tolerance in the collector slope is recommended within $3^{\circ}$ on positive side of the baseline value for winter operation and within $\pm 3^{\circ}$ for year round operation.

\section{Appendices}

\section{A. Wind Heat Transfer Coefficient}

For the estimate of the wind heat transfer coefficient, various correlations have been proposed. McAdams [28] proposed the following correlation on the basis of experimental data of Jurges for a $0.5 \mathrm{~m}^{2}$ square plate:

$$
h_{w}=5.6214+3.912 V_{w}, \quad \text { for } V_{w}<4.88 \mathrm{~ms}^{-1},
$$

where $V_{w}$ is wind speed in $\mathrm{ms}^{-1}$ and $h_{w}$ is the average wind heat transfer coefficient over the collector glazing surface. Khan et al. [29] have supported the correlation of McAdams.

Watmuff et al. [30] opined that the effects of natural convection and radiation are also included in McAdam's relation. Excluding these effects from the McAdam's correlation, they presented the following expression:

$$
h_{w}=2.8+3.0 V_{w}, \quad \text { for } V_{w}<7 \mathrm{~ms}^{-1} \text {. }
$$

Kumar et al. [31] proposed the following correlation, on the basis of indoor experiments on box-type solar cooker:

$$
h_{w}=10.03+4.68 V_{w} \text {. }
$$

Test et al. [32] experimentally determined the convective heat transfer coefficient from the surface of a rectangular plate of size $1.22 \mathrm{~m} \times 0.813 \mathrm{~m}$. Kumar et al. [31] and Akhtar and Mullick [33] observed that, in the outdoor environment, the wind heat transfer coefficient is greater than the values reported from wind tunnel tests and proposed the following correlation:

$$
h_{w}=(8.355 \pm 0.86)+(2.56 \pm 0.32) V_{w} \text {. }
$$

Kumar and Mullick [34] determined experimentally the wind heat transfer coefficient at low wind velocities $\left(V_{w}<\right.$ $0.37 \mathrm{~ms}^{-1}$ ) from a metal plate exposed to solar radiation and presented a correlation of the wind heat transfer coefficient
TABLE 4: Estimate of the wind heat transfer coefficient $h_{w}, \mathrm{Wm}^{-2} \mathrm{~K}^{-1}$.

\begin{tabular}{lccccc}
\hline $\begin{array}{l}V_{w} \\
\left(\mathrm{~ms}^{-1}\right)\end{array}$ & $\begin{array}{c}\text { Equation } \\
\text { (A.1) }\end{array}$ & $\begin{array}{c}\text { Equation } \\
\text { (A.2) }\end{array}$ & $\begin{array}{c}\text { Equation } \\
\text { (A.3) }\end{array}$ & $\begin{array}{c}\text { Equation } \\
\text { (A.4) }\end{array}$ & Range* \\
\hline 0.0 & 5.6 & 2.8 & 10.0 & $7.5-9.2$ & $5.6-10.0$ \\
1.0 & 9.5 & 5.8 & 14.7 & $9.7-12.1$ & $9.5-14.7$ \\
2.0 & 13.5 & 8.8 & 19.4 & $12.0-15.0$ & $12.0-19.4$ \\
\hline
\end{tabular}

${ }^{*}$ Neglecting values from (A.2).

in terms of the temperature excess (surface temperature over the ambient temperature) as

$$
h_{w}=0.8046\left(T_{s}-T_{a}\right)^{0.69} .
$$

The basic heat transfer correlations for natural convection from a heated horizontal plate are [17]

$$
\begin{aligned}
\mathrm{Nu} & =0.54(\mathrm{Gr} \cdot \mathrm{Pr})^{0.25} \\
\text { for } 10^{5} & <(\mathrm{Gr} \cdot \mathrm{Pr})<2 \times 10^{7}, \\
\mathrm{Nu} & =0.15(\mathrm{Gr} \cdot \mathrm{Pr})^{0.33} \\
\text { for } 2 \times 10^{7} & <(\mathrm{Gr} \cdot \mathrm{Pr})<3 \times 10^{10} .
\end{aligned}
$$

Averages of the mean monthly wind speeds at Jodhpur in December-February (winter) and May-June (summer) are about $1.0 \mathrm{~ms}^{-1}$ and $2.0 \mathrm{~ms}^{-1}$, respectively. It is to note that the variation in the wind velocity has been observed to be greater in the summer as compared to the variation in winter at Jodhpur. Table 4 lists the values of the wind heat transfer coefficient as determined from the various wind heat transfer coefficient relations at these wind velocities along with the values at no wind condition (when only natural convection is present). Since the value of the wind heat transfer coefficient given by (A.2) at $V_{w}=0 \mathrm{~m} / \mathrm{s}$ has been found to be even lower than the free convection heat transfer value determined from (A.6a) and (A.6b) for a horizontal plate, the range of the predicted values shown in the last column of the table does not consider the values determined from (A.2). This conclusion is in line with that of Kumar and Mullick [34]. They have reported experimentally determined values of $6 \mathrm{Wm}^{-2} \mathrm{~K}^{-1}$ and $8 \mathrm{Wm}^{-2} \mathrm{~K}^{-1}$ at no wind condition and $0.1 \mathrm{~ms}^{-1}$, respectively.

Based on the discussion presented above, the average values of the wind heat transfer coefficient of $12 \mathrm{Wm}^{-2} \mathrm{~K}^{-1}$ and $15 \mathrm{Wm}^{-2} \mathrm{~K}^{-1}$ from Table 4 at wind velocities of $1.0 \mathrm{~ms}^{-1}$ and $2.0 \mathrm{~ms}^{-1}$ for winter and summer operations, respectively, have been considered in the present study.

\section{B. Sky Temperature}

The sky can be considered as a blackbody at some fictitious temperature known as sky temperature $T_{\text {sky }}$ at which it is exchanging heat by radiation from a terrestrial body. It is a common knowledge that this sky temperature varies from place to place and depends on the sky condition, which varies because of the variation in humidity and pollution, and 
TABLE 5: Estimated values of the sky temperature, K.

\begin{tabular}{lccc}
\hline$T_{a}, \mathrm{~K}$ & Equation (12) & Equation (B.1) & Difference, K \\
\hline 283 & 262.8 & 277 & 14.2 \\
293 & 276.85 & 287 & 10.15 \\
303 & 291.14 & 297 & 5.86 \\
313 & 305.67 & 307 & 1.33 \\
\hline
\end{tabular}

hence the uncertainty in the estimate and variation of the sky temperature is inevitable.

One widely used relation due to Swinbank for clear sky is given as (12). Another approximate empirical relation is also available [35], which is

$$
T_{\text {sky }}=T_{a}-6 .
$$

A comparison of the predicted values of the sky temperature from (12) and (B.1) has been presented in Table 5. The difference is significant at lower ambient temperature values.

Nowak [8] compared the calculated and measured sky temperatures for a horizontal surface and concluded that, in the case of large city areas, the sky temperature may be about $10^{\circ} \mathrm{C}$ higher than the calculated value from (12) because of the atmospheric pollution.

It is to note that sky temperature measurement data for Jodhpur are not available in the open literature.

The temperature of the sky and clouds far overhead can be measured with an infrared thermometer by pointing the thermometer straight up at the open sky or a cloud [36]. An infrared thermometer can show the impact of water vapor on warming the atmosphere. Nearly all the water vapor in the atmosphere is found in the troposphere, which is the layer of the atmosphere between the surface and around 10 to 15 kilometers. When an infrared thermometer is pointed straight up at the sky, it measures the temperature through a coneshaped column of the troposphere. The "sky temperature" can be thought of as an average of the temperature between the ground and the upper troposphere where water vapor is much less abundant.

Karwa and Chitoshiya [19] recorded the sky temperature by pointing the IR thermometer straight up at the sky (towards the zenith) as suggested by [36] between 10.30 $\mathrm{AM}$ and $1.30 \mathrm{PM}$ for 5 days and compared the observed values with the calculated values from (12), which is basically valid for clear sky conditions. Their comparison indicated significant deviations in the variations of the recorded and calculated values, which can be attributed to the variation of the climatic conditions during the days of their experimentation.

\section{Nomenclature}

A: Area of absorber plate $\left[\mathrm{m}^{2}\right]$

$c_{p}:$ Specific heat of air $\left[\mathrm{Jkg}^{1} \mathrm{~K}^{1}\right]$

$D_{h}$ : Equivalent diameter of duct $=4 W H /[2(W+H)][\mathrm{m}]$

$f:$ Friction factor $[-]$ g: Acceleration due to gravity $\left[\mathrm{ms}^{2}\right]$

G: $\quad$ Mass flow rate per unit area of plate $\left[\mathrm{kgs}^{1} \mathrm{~m}^{2}\right]$

$h$ : Heat transfer coefficient $\left[\mathrm{Wm}^{2} \mathrm{~K}^{1}\right]$

$h_{w}: \quad$ Wind heat transfer coefficient $\left[\mathrm{Wm}^{2} \mathrm{~K}^{1}\right]$

$H$ : Height of duct [m]

I: $\quad$ Solar insolation (radiation intensity)

$\left[\mathrm{Wm}^{2}\right]$

$k$ : Thermal conductivity of air $\left[\mathrm{Wm}^{1} \mathrm{~K}^{1}\right]$

$L: \quad$ Length of collector $[\mathrm{m}]$

$m: \quad$ Mass flow rate $\left[\mathrm{kgs}^{1}\right]$

$\dot{m}: \quad$ Mass velocity $=(m / W H)\left[\mathrm{kgs}^{1} \mathrm{~m}^{2}\right]$

Nu: Nusselt number [-]

$P: \quad$ Pumping power [W]

Pr: Prandtl number [-]

Q: $\quad$ Heat collection rate, useful heat gain [W]

$Q_{L}:$ Heat loss [W]

Ra: Rayleigh number [-]

Re: Reynolds number [-]

$T_{a}: \quad$ Ambient temperature $[\mathrm{K}]$

$T_{f m}:$ Mean air temperature $=\left(T_{o}+T_{i}\right) / 2[\mathrm{~K}]$

$T_{i}: \quad$ Inlet air temperature $[\mathrm{K}]$

$T_{m}: \quad$ Mean temperature $[\mathrm{K}]$

$T_{m p g}:$ Mean of the plate and glass temperatures = $\left(T_{p}+T_{g i}\right) / 2[\mathrm{~K}]$

$T_{o}$ : Outlet air temperature $[\mathrm{K}]$

$T_{p}$ : $\quad$ Mean plate temperature $[\mathrm{K}]$

$T_{\text {sky }}:$ Sky temperature $[\mathrm{K}]$

$U_{L}$ : Overall loss coefficient $\left[\mathrm{Wm}^{2} \mathrm{~K}^{1}\right]$

$W$ : Width of duct [m].

\section{Greek Symbols}

$\beta: \quad$ Collector slope $\left[{ }^{\circ}\right]$

$\delta_{p g}:$ Gap between the absorber plate and glass cover $[\mathrm{m}]$

$\delta p: \quad$ Pressure drop across duct $\left[\mathrm{Nm}^{2}\right]$

$\Delta T: \quad$ Temperature rise of air $\left[{ }^{\circ} \mathrm{C}\right]$

$\Delta \eta: \quad$ Change in thermal efficiency of collector [-]

$\Delta \eta_{e}$ : Change in effective efficiency of collector [-]

$\eta: \quad$ Thermal efficiency of collector [-]

$\eta_{e}: \quad$ Effective efficiency of collector [-]

$\varepsilon: \quad$ Emissivity [-]

$v_{m p g}$ : Kinematic viscosity of air at temperature $T_{m p g}\left[\mathrm{~m}^{2} \mathrm{~s}^{1}\right]$

$\rho: \quad$ Density of air $\left[\mathrm{kgm}^{3}\right]$

$\tau \alpha: \quad$ Transmittance-absorptance product [-]

$\mu: \quad$ Dynamic viscosity of air $[\mathrm{Pa} \cdot \mathrm{s}]$.

\section{Subscripts}

$b$ : Duct bottom surface

$g$ : Glass

$m$ : Mean

p: Plate. 


\section{Conflict of Interests}

The authors declare that there is no conflict of interests regarding the publication of this paper. Further, they do not have a direct financial relation that might lead to a conflict of interests for any of the authors.

\section{References}

[1] R. Karwa, S. N. Garg, and A. K. Arya, "Thermo-hydraulic performance of a solar air heater with n-subcollectors in series and parallel configuration," Energy, vol. 27, no. 9, pp. 807-812, 2002.

[2] D. Njomo and M. Daguenet, "Sensitivity analysis of thermal performances of flat plate solar air heaters," Heat and Mass Transfer, vol. 42, no. 12, pp. 1065-1081, 2006.

[3] M. K. Gupta and S. C. Kaushik, "Exergetic performance evaluation and parametric studies of solar air heater," Energy, vol. 33, no. 11, pp. 1691-1702, 2008.

[4] E. K. Summers, J. H. Lienhard, and S. M. Zubair, "Air-heating solar collectors for humidification-dehumidification desalination systems," Journal of Solar Energy Engineering, Transactions of the ASME, vol. 133, no. 1, 6 pages, 2011.

[5] J. G. Symons and R. Gani, “Thermal performance predictions and sensitivity analysis for high temperature flat-plate solar collectors," Solar Energy, vol. 24, no. 4, pp. 407-410, 1980.

[6] R. Karwa and K. Chauhan, "Performance evaluation of solar air heaters having $\mathrm{v}$-down discrete rib roughness on the absorber plate," Energy, vol. 35, no. 1, pp. 398-409, 2010.

[7] S. A. Klein, "Calculation of flat-plate collector loss coefficients," Solar Energy, vol. 17, no. 1, pp. 79-80, 1975.

[8] H. Nowak, "The sky temperature in net radiant heat loss calculations from low-sloped roofs," Infrared Physics, vol. 29, no. 2-4, pp. 231-232, 1989.

[9] W. C. Swinbank, "Long-wave radiation from clear skies," Quarterly Journal of the Royal Meteorological Society, vol. 89, pp. 339348, 1963.

[10] H. Buchberg, I. Catton, and D. K. Edwards, "Natural convection in enclosed spaces-a review of application to solar energy collection," Journal of Heat Transfer, vol. 98, no. 2, pp. 182-188, 1976.

[11] P. W. Niles, E. J. Carnegie, J. G. Pohl, and J. M. Cherne, "Design and performance of an air collector for industrial crop dehydration," Solar Energy, vol. 20, no. 1, pp. 19-23, 1978.

[12] R. Karwa, N. Karwa, R. Misra, and P. C. Agarwal, "Effect of flow maldistribution on thermal performance of a solar air heater array with subcollectors in parallel," Energy, vol. 32, no. 7, pp. 1260-1270, 2007.

[13] M. A. Ebadian and Z. F. Dong, "Forced convection, internal flow in ducts," in Handbook of Heat Transfer, W. M. Rohsenow, J. P. Hartnett, and Y. I. Cho, Eds., chapter 5, McGraw-Hill, New York, NY, USA, 1998.

[14] K. G. T. Hollands and E. C. Shewen, "Optimization of flow passage geometry for air-heating, plate-type solar collectors," Journal of Solar Energy Engineering, vol. 103, no. 4, pp. 323-330, 1981.

[15] M. S. Bhatti and R. K. Shah, "Turbulent and transition flow convective heat transfer," in Handbook of Single-phase Convective Heat Transfer, S. Kakac, R. K. Shah, and W. Aung, Eds., chapter 4, John Wiley \& Sons, New York, NY, USA, 1987.

[16] A. Cortés and R. Piacentini, "Improvement of the efficiency of a bare solar collector by means of turbulence promoters," Applied Energy, vol. 36, no. 4, pp. 253-261, 1990.
[17] J. P. Holman, Heat Transfer, McGraw-Hill, New York, NY, USA, 7th edition, 1992.

[18] R. Karwa, S. C. Solanki, and J. S. Saini, "Thermo-hydraulic performance of solar air heaters having integral chamfered rib roughness on absorber plates," Energy, vol. 26, no. 2, pp. 161-176, 2001.

[19] R. Karwa and G. Chitoshiya, "Performance study of solar air heater having v-down discrete ribs onabsorber plate," Energy, vol. 55, pp. 939-955, 2013.

[20] U. R. Lenel and P. R. Mudd, "A review of materials for solar heating systems for domestic hot water," Solar Energy, vol. 32, no. 1, pp. 109-120, 1984.

[21] J. R. Kreider and F. Kreith, Solar Energy Handbook, McGrawHill, New York, NY, USA, 1981.

[22] J. A. Duffie and W. A. Beckman, Solar Engineering of Thermal Processes, Wiley, New York, NY, USA, 1982.

[23] R. Karwa and V. Srivastava, "Thermal performance of solar air heater having absorber plate with $\mathrm{v}$-down discrete rib roughness for space-heating applications," Journal of Renewable Energy, vol. 2013, Article ID 151578, 13 pages, 2013.

[24] S. Barbarino, F. Grasso, G. Guerriera, F. Musumeci, A. Scordino, and A. Triglia, "Surface roughness effect on optical absorptivity of metals," Applied Physics A, vol. 29, no. 2, pp. 77-80, 1982.

[25] C.-D. Wen and I. Mudawar, "Experimental investigation of emissivity of aluminum alloys and temperature determination using multispectral radiation thermometry (MRT) algorithms," Journal of Materials Engineering and Performance, vol. 11, no. 5, pp. 551-562, 2002.

[26] M. Abdolzadeha and M. A. Mehrabianb, "Obtaining maximum input heat gain on a solar collector under optimum slope angle," International Journal of Sustainable Energy, vol. 30, no. 6, pp. 353-366, 2011.

[27] J. H. Wasley and M. Utzinger, "Vital signs curriculum materials project, glazing performance," Johnson Controls Institute for Environmental Quality in Architecture, School of Architecture and Urban Planning, University of WisconsinMilwaukee, Wis, USA, 1996, http://arch.ced.berkeley.edu/vitalsigns/res/downloads/rp/glazing/glazl-bg.pdf.

[28] W. H. McAdams, Heat Transmission, McGraw-Hill, New York, NY, USA, 1954.

[29] S. Y. Khan, N. Akhtar, and S. C. Mullick, "Indoor experimental validation of glass-cover temperatures and upward heat-flow coefficients of a single glazed flat-plate solar collectors," Journal of Solar Energy, vol. 11, pp. 65-71, 2001.

[30] J. H. Watmuff, W. W. S. Charters, and D. Proctor, "Solar and wind induced external coefficients-solar collectors," in Revue Internationale D'Heliotechnique, vol. 56, Cooperation Mediterraneenne pour l'Energie Solaire, 1977.

[31] S. Kumar, V. B. Sharma, T. C. Kandpal, and S. C. Mullick, "Wind induced heat losses from outer cover of solar collectors," Renewable Energy, vol. 10, no. 4, pp. 613-616, 1997.

[32] F. L. Test, R. C. Lessmann, and A. Johary, "Heat transfer during wind flow over rectangular bodies in the natural environment," Journal of Heat Transfer, vol. 103, no. 2, pp. 262-267, 1981.

[33] N. Akhtar and S. C. Mullick, "Existing correlations for wind heat transfer coefficients and impact on the top heat loss factor of flat-plate collectors with a single glass cover," Journal of Solar Energy Society of India, vol. 8, no. 2, pp. 105-112, 1998.

[34] S. Kumar and S. C. Mullick, "Convective heat transfer from the top outermost cover of a flat plate solar collector at low wind speeds," Journal of Solar Energy Society of India, vol. 17, no. 1-2, pp. 87-93, 2007. 
[35] H. P. Garg and J. Prakash, Solar Energy: Fundamentals and Applications, Tata-McGraw-Hill, New Delhi, India, 2000.

[36] https://mynasadata.larc.nasa.gov/P18a.html, 2012. 


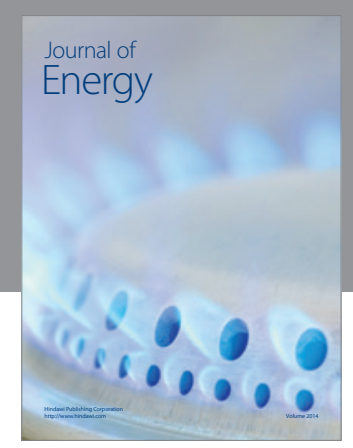

Journal of

Industrial Engineering
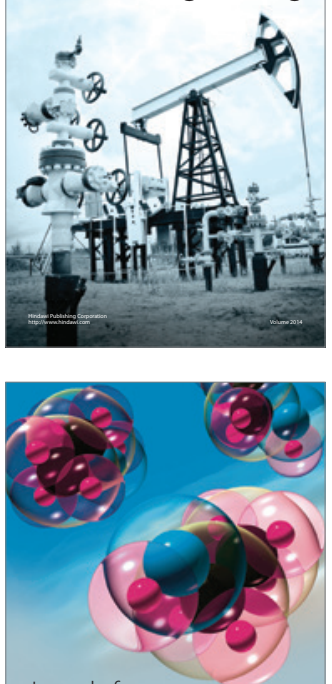

Fuels
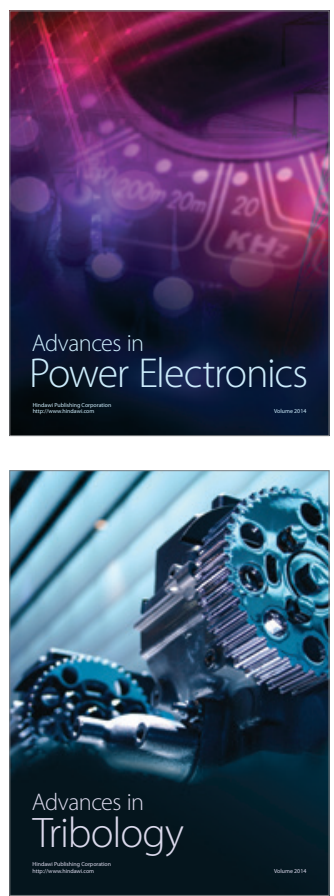

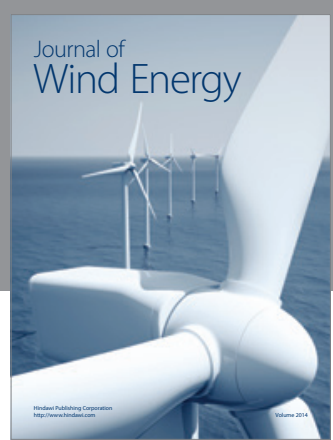

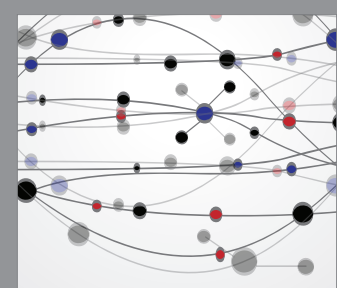

The Scientific World Journal

Submit your manuscripts at http://www.hindawi.com

Journal of

Structures
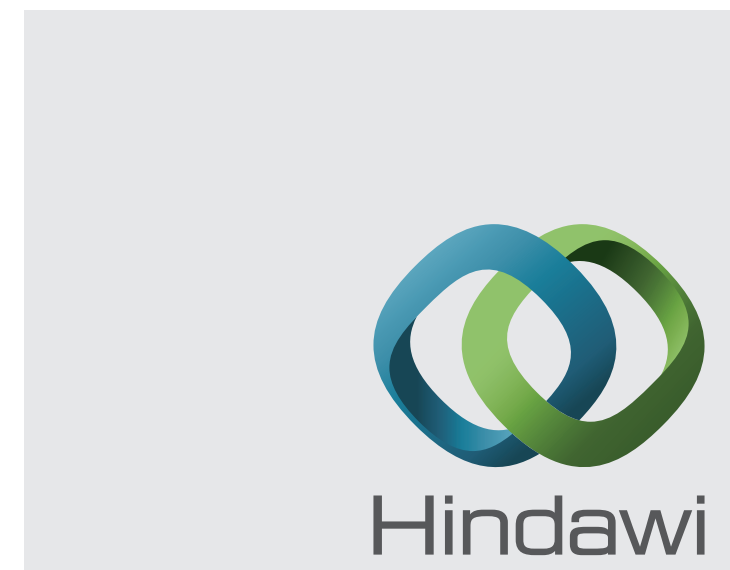

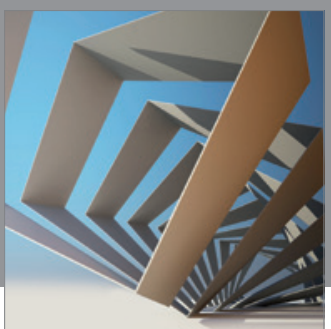

Rotating

Machinery
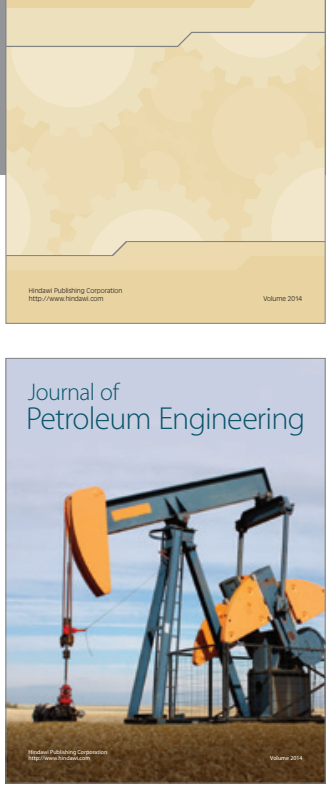

Journal of

Solar Energy
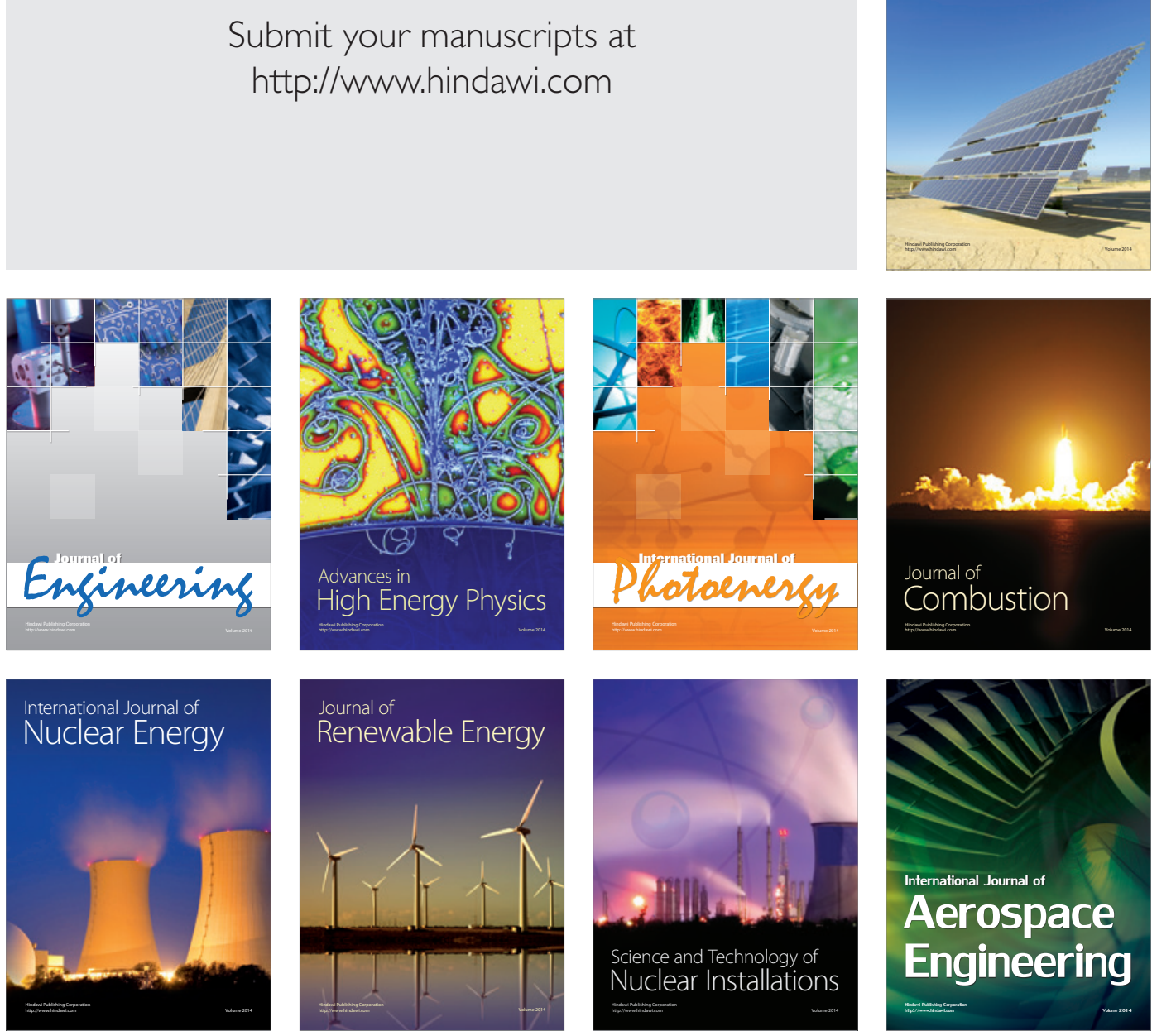